\title{
MULTIPLE COMPLEMENTARY STUDIES CLARIFY WHICH CO-OCCURRING CONGENER PRESENTS THE GREATEST HYBRIDIZATION THREAT TO A RARE TEXAS ENDEMIC WILDFLOWER (HIBISCUS DASYCALYX: MALVACEAE)
}

\author{
Melody P. Sain ${ }^{*}$, Julia Norrell-Tober ${ }^{*}$, Katherine Barthel, Megan Seawright, \\ Alyssa Blanton, Kate L. Hertweck ${ }^{2}$, John S. Placyk, Jr. ${ }^{3}$ \\ Department of Biology and Center for Environment, Biodiversity, and Conservation \\ University of Texas at Tyler \\ 3900 University Blvd., Tyler, Texas 75799, U.S.A.
}

\author{
Randall Small \\ Department of Ecology \& Evolutionary Biology \\ University of Tennessee-Knoxville \\ Dabney Hall, 1416 Circle Dr., Knoxville, Tennessee 37996, U.S.A. \\ rsmall@utk.edu
}

\author{
Lance R. Williams, Marsha G. Williams, Joshua A. Banta \\ Department of Biology and Center for Environment, Biodiversity, and Conservation \\ University of Texas at Tyler \\ 3900 University Blvd., Tyler, Texas 75799, U.S.A. \\ Iwilliams@uttyler.edu, mwilliams@uttyler.edu, jbanta@uttyler.edu
}

\footnotetext{
"The two authors contributed equally to this work.

1Current address: Department of Botany, University of Wisconsin, Madison, Madison, Wisconsin 53706, U.S.A., msain@wisc.edu 2Current address: Fred Hutchinson Cancer Research Center, 1100 Fairview Ave. N, Seattle, Washington 98109, U.S.A., K8hertweck@gmail.com 3Current address: Trinity Valley Community College, 100 Cardinal Dr., Athens, Texas 75751, U.S.A., john.placyk@tvcc.edu
}

ABSTRACT

The Neches River Rose Mallow (Hibiscus dasycalyx) is a rare wildflower endemic to Texas that is federally protected in the U.S.A. While previous work suggests that $H$. dasycalyx may be hybridizing with its widespread congeners, the Halberd-leaved Rose Mallow (H. laevis) and the Woolly Rose Mallow (H. moscheutos), this has not been studied in detail. We evaluated the relative threats to H. dasycalyx posed by hybridization with $H$. laevis and $H$. moscheutos by 1) examining their relatedness to one another via modern phylogenomic methods, 2) examining their ecological (dis)similarities to one another using ecological niche modeling, and 3) looking for genomic evidence of hybridization among them. Our results suggest that $H$. dasycalyx is very closely related and ecologically similar to $H$. laevis, and that $H$. laevis is interbreeding with $H$. dasycalyx in the wild. Conversely, H. moscheutos appears to be more distantly related to H. dasycalyx and more ecologically dissimilar, and the two are most likely not hybridizing. For these reasons, we believe that $H$. laevis poses a greater threat to $H$. dasycalyx than H. moscheutos. We offer some hypotheses as to why H. dasycalyx and H. laevis are coming into secondary contact where hybridization can occur.

Key Words: Hibiscus, Ecological Niche Modeling, Conservation, Phylogenetics, Phylogenomics, RADseq, nextRAD, SNPs, Phylogenetics, Population Genetics, STRUCTURE, GRANULE-BOUND STARCH SYNTHASE I

\section{RESUMEN}

El hibisco del río Neches (Hibiscus dasycalyx) es una rara flor silvestre endémica de Texas que está protegida federalmente en los Estados Unidos. Mientras que trabajos anteriores sugieren que H. dasycalyx puede estar hibridando con sus congéneres de amplia distribución, el hibisco de hojas de alabarda (H. laevis) y el hibisco lanoso (H. moscheutos), pero esto no se ha estudiado en detalle. Se evaluaron las amenazas relativas a $H$. dasycalyx planteadas por la hibridación con $H$. laevis y $H$. moscheutos mediante l) el examen de su relación a través de métodos filogenómicos modernos, 2) el examen de las (di)similitudes ecológicas entre las especies mediante el modelado de nicho ecológico, y 3) la búsqueda de evidencia genómica de hibridación entre las tres especies. Nuestros resultados sugieren que $H$. dasycalyx está muy estrechamente relacionada y es ecológicamente similar a H. laevis, y que H. laevis se está cruzando con $H$. dasycalyx en la naturaleza. Por el contrario, H. moscheutos parece estar más distantemente relacionada con $H$. dasycalyx y es ecológicamente diferente, y lo más probable es que entre 
ambas no haya hibridación. Por estas razones, creemos que H. laevis representa una amenaza mayor para H. dasycalyx que H. moscheutos. Ofrecemos algunas hipótesis en cuanto a porqué H. dasycalyx y H. laevis están entrando en contacto secundario donde puede ocurrir la hibridación.

\section{INTRODUCTION}

Conservation biology assumes that biodiversity is discrete, making it possible to preserve distinct taxa. Yet this assumption is challenged in the early stages of the speciation process, when ecological, morphological, and genetic similarities among diverging groups make reproductive isolation incomplete (Fitzpatrick et al. 2015). Hybridization is a risk factor when conserving recently diverged groups, because the gene pool of a rare species can be swamped out of existence by frequent hybridization and backcrossing with a more common one (Rhymer \& Simberloff 1996; Fitzpatrick et al. 2015; Todesco et al. 2016; Galaverni et al. 2017). This is especially relevant if the contact between them is facilitated by anthropogenic habitat alterations that enable the spread of the more common species into areas occupied by the rarer species (Allendorf et al. 2001; Laikre et al. 2010). Researchers can assess the hybridization threat of co-occurring, congeneric taxa to a rare species in several ways. One way is to evaluate how closely related other species are to the rare species, because reproductive isolating barriers generally accumulate through time; all else being equal, the more closely related species, and especially sister species, should more readily hybridize (Muller 1942; Matute et al. 2010; Fitzpatrick et al. 2015). Another way to assess the hybridization threat is to evaluate how ecologically (dis)similar the species are. Species that are more ecologically different from one another should accumulate more reproductive isolating barriers, as compared to more ecologically similar species, due to divergent selection between their different environments and, therefore, selection against hybrids (Nosil et al. 2003; Coyne \& Orr 2004; Gow et al. 2007; Hendry et al. 2007). Thus, more closely related, ecologically similar species should pose a greater hybridization threat to a rare species than more distantly related, ecologically dissimilar species. Another way to assess the hybridization threat is to document evidence of hybridization in the genome (Fitzpatrick et al. 2015; Vuillaume et al. 2015; Daco et al. 2019).

The threat posed by hybridization with co-occurring congeners is an important consideration for the rare Texas endemic wildflower, the Neches River Rose Mallow (Hibiscus dasycalyx S.F. Blake \& Shiller; Malvaceae). First described in 1958 based on morphological characteristics (Blake 1958), it was recently listed as a threatened species under the Endangered Species Act by the U.S. Fish \& Wildlife Service (2013). Hibiscus dasycalyx is a shrubby perennial marsh plant that is endemic to East Texas (Klips 1995; Mendoza 2004), and is found in three counties (Cherokee, Houston, and Trinity), in three watersheds (Angelina, Neches, and Trinity), where it grows seasonally on wet alluvial soils that are flooded in late winter and early spring but dry out in summer (Texas Parks \& Wildlife Department n.d.). Previous studies have found morphological and molecular evidence of hybridization between $H$. dasycalyx and its co-occurring and widespread congeners, the Swamp Rose Mallow (H. moscheutos L.) and the Halberd-leaved Rose Mallow (H. laevis All.) (Blanchard 1976; Klips 1995; Mendoza 2004; Small 2004). All three species are diploid and cross-fertile in the laboratory (Klips 1995), although artificial crosses suggest that successful hybridization between H. laevis and H. dasycalyx is much more likely than successful hybridization between H. moscheutos and H. dasycalyx (Wise \& Menzel 1971). In addition, $H$. dasycalyx often co-occurs with $H$. laevis and H. moscheutos without any obvious barriers to interspecific reproduction (Correll \& Correll 1972; Blanchard 1976; Klips 1995).

A related conservation issue is that delineation of rare entities from more common ones is haphazard. Many rare species were described many decades ago, based on morphology alone, which is subject to arbitrary lumping or splitting of taxa without regard to the actual evolutionary relationships among groups (Rojas 1992; Faurby et al. 2016; Garnett \& Christidis 2017; Delić et al. 2017). Furthermore, purely morphological assessments of taxonomic boundaries can miss cryptic speciation events (Katolikova et al. 2016; Delić et al. 2017). Altogether, this means that multiple approaches need to be put to bear on taxa important to conservation in order to understand what distinguishes the rare species from more common ones, as well as to understand how much of a threat exists of genetic swamping of the rare species by hybridization with the common ones. We cannot base our conclusions on morphology alone. 
In this study, we used genetic and ecological data to assess historical and contemporary patterns in $H$. dasycalyx and related taxa. We provide data that helps evaluate the relative threats to $H$. dasycalyx posed by hybridization with $H$. laevis versus $H$. moscheutos by answering three questions. First, how are the three species related to each other? Species that are more closely related should have accrued fewer genetic isolating mechanisms than more distantly related species (Muller 1942; Matute et al. 2010). Previous studies (Blanchard 1976; Klips 1995; Small 2004) suggested that H. laevis and H. dasycalyx are monophyletic sister groups that are more distantly related to H. moscheutos. To test this hypothesis and determine with more rigor which species is most closely related to H. dasycalyx, we applied phylogenomic methods (Rodríguez et al. 2017; DaCosta et al. 2019; Young \& Gillung 2020) utilizing multiple individuals of $H$. dasycalyx and its co-occurring congeners and thousands of genome-wide RADseq DNA markers (Davey et al. 2011). When considering only relatedness as a criterion, we expect the species closely related to $H$. dasycalyx to pose the greatest threat through hybridization.

Second, how ecologically (dis)similar are the three species to one another? Species that are more ecologically dissimilar could have acquired stronger isolating mechanisms because of selection against hybrids (Nosil et al. 2003; Coyne \& Orr 2004; Gow et al. 2007; Hendry et al. 2007), and therefore present less of a hybridization threat. We examined the species' ecological (dis)similarities to one another using ecological niche modeling (Wiens \& Graham 2005; Raxworthy et al. 2007; Walters et al. 2017), which combines the locations of multiple individuals of each species from throughout their co-occurring range in Texas with environmental data to determine habitat preferences. When considering only ecological similarity as a criterion, the species that is more ecologically similar to $H$. dasycalyx should pose the greatest hybridization threat.

Third, is there evidence of hybridization in the H. dasycalyx genome? We used two approaches to look for historical patterns of hybridization. The first approach involved sequencing multiple individuals of each species for the nuclear gene GRANULE-BOUND STARCH SYNTHASE I (GBSSI) following Small (2004) and reconstructing a gene tree from pseudophased allelic haplotypes. Evidence for hybridization and introgression represented by one or more alleles from the same individual residing in haplogroups associated with another species (Small 2004). The second approach assessed introgression via a genome-wide nextRAD data (BlancoBercial \& Bucklin 2016). We sampled individuals of all three species, concentrating on a hybrid zone known as Boggy Slough, where H. dasycalyx, H. laevis, and morphological intermediates occur. We analyzed the data using a Bayesian clustering approach to visualize admixture among different inferred ancestral groups comprising the specimens (Pritchard et al. 2000).

\section{MATERIALS AND METHODS}

\section{Background}

Plant material.-The Rose Mallows, Hibiscus L. sect. Muenchhusia (Heister ex Fabricius) O.J. Blanch. (Malvaceae), are a North American taxon that consist of five closely related species (Blanchard 1976). The five species included in this taxon are the Scarlet Rose Mallow (Hibiscus coccineus Walter), the Neches River Rose Mallow (Hibiscus dasycalyx Blake \& Shiller), the Swamp Rose Mallow (Hibiscus grandiflorus Michx.), the Halberd-leaved Rose Mallow (Hibiscus laevis All.), and the Woolly Rose Mallow (Hibiscus moscheutos L.). There are two subspecies within H. moscheutos that Blanchard (1976) recognized as H. moscheutos subsp. moscheutos (synonymous with H. moscheutos subsp. palustris L.) of the northeastern U.S.A. and H. moscheutos subsp. lasiocarpos (Cav.) O.J. Blanch. (synonymous with H. moscheutos subsp. incanus Wendl.) of the southeastern coastal plains (Blanchard 1976). Hibiscus sect. Muenchhusia was separated from the large Hibiscus sect. Trionum by Blanchard (Fryxell 1988). The separation of sect. Muenchhusia as a monophyletic group was proposed from the taxon's overall shared chromosome number $(n=19$; Wise \& Menzel 1971), ecological similarities of being primarily wetland species, similar morphological characteristics of individuals, a shared growth habit, and a common geographic distribution (Blanchard 1976).

Although Blanchard's (1976) descriptive taxonomic work furthered systematics within Hibiscus, it did not address the phylogenetic relationship of the species within sect. Muenchhusia. Blanchard (1976) was only able to note that H. dasycalyx had strong similarities to H. laevis and that plants observed at the type location (Apple 
Springs in Trinity County; Blake 1958) resembled the type specimen, and that wild-type specimen seeds produced viable fertile offspring consistent with the description of $H$. dasycalyx and produced viable seeds. Wise and Menzel (1971) also added that within sect. Muenchhusia there were two distinct groups that consisted of Group I, H. grandifloras and H. moscheutos, and Group II, H. coccineus and H. laevis, and that crosses within groups produced fertile hybrids whereas between group crosses produced hybrids that were in general unable to produce fruiting bodies. Small (2004) later placed H. dasycalyx within Group II.

The focus of this study is on three of these mallows: H. dasycalyx, the federally threatened Texas-endemic species, and two sympatric, congeneric species, H. laevis and H. moscheutos subsp. lasiocarpos (Correll \& Correll 1972; Blanchard 1976), which are the only species within sect. Muenchhusia with which it co-occurs. Hibiscus moscheutos subsp. lasiocarpos (referred to hereafter as H. moscheutos) is the only subspecies of H. moscheutos encountered in this study. It is the one whose distribution falls within that of H. dasycalyx and H. laevis (Blanchard 1976). In any event, the Committee on the Status of Endangered Wildlife in Canada (2004) suggests that all $\mathrm{H}$. moscheutos specimens should simply be regarded as H. moscheutos L. due to the wide range of intermediate morphologies that are observed (see also Winters 1970).

This previous literature differentiating the three species based on morphological and ecological characteristics, as well as the previous listing of $H$. dasycalyx as a federally protected plant, indicate they are wellestablished species able to be differentiated taxonomically. There are several diagnostic morphological characteristics that distinguish the three taxa, as described by Blanchard (1976):

Hibiscus laevis possess vegetative parts that are completely glabrous, and leaves that are hastately threelobed. The middle leaf lobe is two to six times as long as the width of the leaf and long-acuminate. Calyces and capsules are also glabrous or nearly glabrous, and petals moderately spread beyond the calyx tube and are of pink or white color with a red base. Seeds tend to have a reddish-pubescent appearance.

Hibiscus dasycalyx possess vegetative parts that are glabrous, and leaves that are deeply and narrowly three-lobed. Calyces and capsules are densely hirsute, and petals moderately spread beyond the calyx tube and are of white color with a red base. Seeds tend to have a reddish-pubescent appearance. Overall, Hibiscus dasycalyx is very similar to H. laevis, except for its highly pubescent calyx and fruit and extremely narrowly and deeply lobed leaves.

Hibiscus moscheutos is characterized by vegetative structures that are pubescent to a certain degree (Klips 1995). The leaf is unlobed to broadly triangular-ovate. The calyx has star shaped hairs and is densely pubescent with matted, soft white woolly hairs. The capsule is variously pubescent, with hair ranging from simple, or stellate, to glandular. The petals are usually white or pink, with a red base in the center, near the calyx, and like the previous Hibiscus species they are bee-pollinated (Klips 1995).

\section{Genome-wide phylogenomic analysis}

DNA Extraction and RAD-Seq Data Acquisition and Bioinformatic Analysis.-Six H. dasycalyx specimens, four H. laevis specimens, and five H. moscheutos specimens were used for this study. The H. laevis and H. moscheutos specimens were collected from wild populations from June-October 2014 (Figs. 1, S1). The H. dasycalyx specimens were collected in April 2016 from the naturally occurring H. dasycalyx preserve in Lovelady, Texas (Texas Land Conservancy 2015). An H. trionum specimen was used as an outgroup, because the section in which it is placed (Trionum) is closely related to sect. Muenchhusia, and this outgroup has been used in previous studies with H. dasycalyx (Small 2004). The specimen was provided by Dr. Edwige Moyroud at the University of Cambridge and originated from a commercial source.

DNA was extracted from young leaves of each plant using a DNeasy Plant Mini Kit (Qiagen). The DNA preparations were then sent to Floragenex (Eugene, Oregon) for restriction-site associated DNA sequencing (RADseq), a next-generation sequencing method that identifies thousands of polymorphic loci genome-wide. RADseq is a fractional genome sequencing strategy designed to interrogate the selected genome (Baird et al. 2008). The Floragenex protocols for library preparation and RADseq were followed. Total genomic DNA was digested with a restriction endonuclease PstI, and then a series of sequencing adapters were ligated to the 

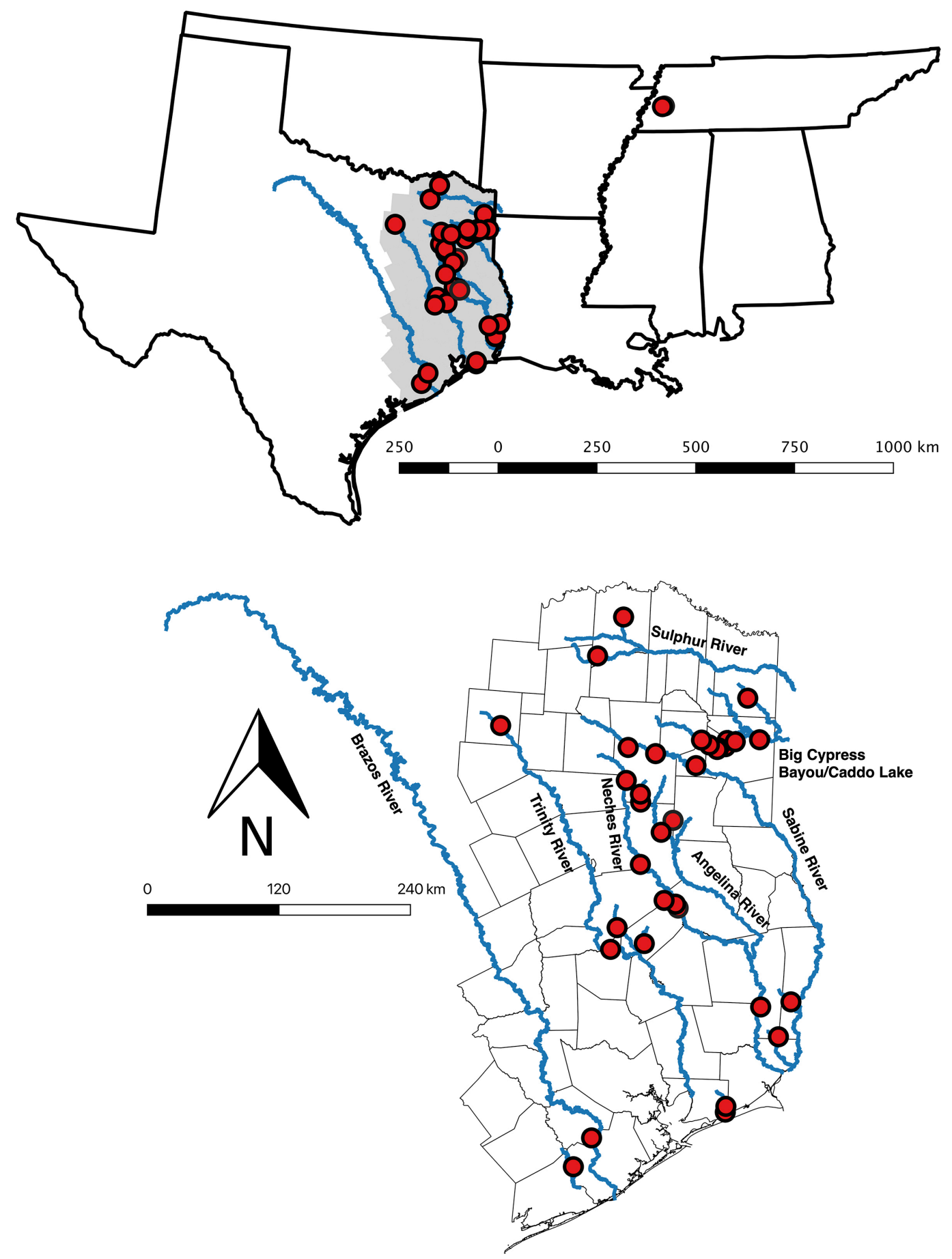

Fig. 1. Locations of all populations of all three species of rose mallow used in this study (red circles) at the full extent (top) and zoomed in to east Texas (bottom). The shaded area at the full extent highlights east Texas. The boundaries at the east Texas extent are counties. The major river systems are labeled at the east Texas extent. Refer to the supplemental information for more details. 
resulting DNA fragments. The DNA fragments were sequenced using Illumina HiSeq2000 (Bentley et al. 2008).

Following Floragenex's standard bioinformatics pipeline, one sample was arbitrarily assembled de novo and used as the pseudoreference. As elaborated in Lamer (2014), the pipeline employed by Floragenex was as follows: BOWTIE (version 0.11.3; Langmead et al. 2009) was used under standard alignment parameters (reads were allowed to map to only one location in the genome with up to three mismatches per alignment. If reads aligned to more than one location within the genome, reads were not considered for SNP variant detection) and SAMtools (0.0.12a; Li et al. 2009) was used under what Floragenex defines as "standard" conditions (minor allele frequency of 0.075 , minimum 49 coverage, minimum phred genotype quality score of 20 and minimum percent of the population genotyped of $65 \%$ ) and custom scripts were used for data management. The program SAMtools tabulated single nucleotide polymorphism (SNP) variants for all individuals (using the 'pileup' module) and data were exported in VARIANT CALL FORMAT 4.1 (VCF). Sequence data has been archived under NCBI BioProject PRJNA382435.

Phylogenetic Inference.-To create a picture of the phylogenetic relationships among the species, which takes into account multiple genomic fragments and multiple individuals (Heled \& Drummond 2010; Davey et al. 2011), a Randomized Axelerated Maximum Likelihood (RAxML) phylogenetic approach was used, which implements a tree search algorithm that returns trees with reliable likelihood scores (Stamatakis 2006). JModeltest 2.16 v20140903 (Darriba et al. 2012) identified a General Time Reversible (GTR) model as the best model of sequence evolution for the concatenated SNP alignment under the Akaike information criterion (AIC). The phylogeny was constructed in RAxML 3.1 using the rapid bootstrapping with subsequent ML search option under a GTR model of evolution with an ascertainment bias correction (ASC), given that only variant SNP sites were included in the alignment (as discussed in the RAxML manual). RAxML assessed support for the phylogeny using non-parametric bootstrap resampling of 10000 replicates (Felsenstein 1981).

A 'multispecies coalescent' approach (Bryant et al. 2012) was also used to construct a Bayesian coalescent phylogeny that estimates the relative time for mutations among randomly sampled pairs of individuals to coalesce back to common ancestors (Liu et al. 2019). The phylogeny was constructed using the program Bayesian Evolutionary Analysis by Sampling Trees (BEAST; Drummond \& Rambaut 2007), with the add-on package SNP and AFLP Package for Phylogenetic analysis (SNAPP; Bryant et al. 2012). This package is designed for inferring species trees and species demographics from independent (unlinked) biallelic markers such as well spaced SNPs (Bryant et al. 2012). This program implements a full coalescent model, but uses a novel algorithm to integrate over all possible gene trees, rather than sampling them explicitly. The analysis used the GTR model of evolution and proceeded for 10,000,000 generations with 1,000,000 (10\%) discarded as burnin. Once the program completed, the results were inspected in Tracer to ensure convergence (Drummond \& Rambaut 2007).

\section{Ecological niche modeling}

The Maxent method for ecological niche modeling uses a general-purpose machine learning method that estimates the probability of a species distribution by finding the probability of a distribution that is closest to uniform and then altering one environmental variable at a time repeatedly to maximize the likelihood of the occurrence dataset (Hernandez et al. 2006; Phillips et al. 2006). Maxent produces a heat map that visualizes a fitted cloglog link function relating the environmental data to the habitat suitability of every parcel of the landscape (at the grain size of the environmental data; Phillips 2017). The habitat suitability scores range on a scale from zero (most unsuitable) to one (most suitable).

The study area was restricted to East Texas including the watersheds of the Trinity, Neches, and Angelina rivers. This extent was based on the historic county range of $H$. dasycalyx and extended to include all of East Texas to incorporate locations for H. laevis and H. moscheutos (Figs. 1, S4). Species occurrence data was obtained for H. dasycalyx, H. laevis, and H. moscheutos via personal collections from the field, herbaria records and iNaturalist records (www.inaturalist.org). To minimize autocorrelation at $1 \mathrm{~km}$, we used the "thin" 
function of the package spThin (Aiello-Lammens et al. 2015) in R version 4.0.2 (R Core Team 2020) to remove all but one entry within that radius.

Five continuous soil variables were incorporated into the models: calcium carbonate concentration (\%); erodibility (Kf, ranges from 0.02 to 0.69 where higher values mean more susceptibility to rill erosion by rainfall; Oregon Department of Transportation 2005); liquid limit of the soil layer (\% moisture by weight); slope of the map unit (\%); and depth to the seasonally high water table $(\mathrm{cm})$. Soil characteristics were obtained from the State Soil Geographic (STATSG0) Data Base (U.S. Department of Agriculture et al. 1995), and the data processing steps used to make this dataset are described by Wolock (1997). All environmental layers and occurrence data were projected to NAD 1983 UTM Zone 15N (units: meters) using ArcMap 10.3. Environmental layers were converted to raster files and resampled to a common resolution of $100 \mathrm{~m} \times 100 \mathrm{~m}$. Then each raster was clipped to the extent of the study area and converted to ASCII files. The environmental layers have Pearson correlation coefficients less than 0.65 amongst one another (appendix), which demonstrates that there is not an excess of redundancy in the information we used.

We used a "leave-one-out" or " $n-1$ " cross-validation method, as previously described by Pearson et al. (2007), which is appropriate for small sample sizes. We set the number of folds for each species to equal the number of samples, so that each fold contained $n-1$ observations, where $n$ is the total sample size. This means that each fold only had a single test data point, and that each observation was the test data point, in turn, for a separate fold. Model statistics were then averaged across the $n$ folds for each species.

Models were validated using the test AUC, or the area under the operator receiving curve. AUC measures the probability that a randomly chosen presence site will be ranked above a randomly chosen pseudoabsence site (Phillips \& Dudik 2008). The test AUCs represent the average percentage of the pseudoabsence data with lower habitat suitability scores than single "test" presence locations left out of the model building process for each model fold. Importantly, this model validation procedure is based on data points (test data) that were naive to the model building process for each model fold, and thus represent a form a ground-truthing of the models with independent data.

To quantify the relative importance of the individual environmental variables to the models, the fit of each full model was compared to reduced univariate models (Phillips et al. 2006). If an environmental variable accounted for a substantial portion of the model fit when modeled by itself (as compared to the full model that was based on all the environmental variables), then the environmental variable was considered an important determinant of habitat suitability (Phillips et al. 2006).

Model fit was measured with the gain statistic. Gain is a likelihood (deviance) statistic that measures the model performance compared to a model that assigns equal habitat suitabilities to all areas of the landscape. Taking the exponent of the final gain gives the (mean) probability of the presence sample(s) compared to the pseudoabsences. For instance, a gain of 3 means that an average presence location has a habitat suitability of $e^{3}$ $=20.1$ times higher than an average pseudoabsence site. The test gains that are reported are the averages of test gains of the single "test" presence locations left out of the model building process for each model fold.

We calculated the differentiation in habitat associations among pairs of species using the "niche overlap" module of ENMTools (Warren et al. 2010). We report both the I statistic and the D statistic, which are highly correlated with one another (Warren et al. 2008). Both statistics range from zero (the habitat associations of the two species are completely different) to one (the habitat associations of the two species are identical; Warren et al. 2008). We then used the "niche identity test" module within ENMTools to do the following: (a) pool the occurrence points of the two species and permute their identities to produce two new samples with the same numbers of observations as the empirical data (Warren et al. 2010); (b) model the habitat associations of the permuted pseudospecies in Maxent; (c) calculate the I and D statistics of the two permuted pseudospecies; (d) repeat this procedure 100 times to generate a permuted (and non-parametric) distribution of $I$ and $D$ statistics under the null hypothesis. Two species were considered to have significantly different habitat associations if the observed (non-permuted) I or $D$ statistic for those species was below the $5^{\text {th }}$ most extreme (small) value from the permuted distribution of those statistics. This corresponds to an empirically derived $5 \%$ chance that 
two models, based on the same underlying habitat associations, would be that different because of sampling effects.

\section{Molecular evidence of hybridization}

Analysis of segregating nuclear haplotypes.-The nuclear gene GRANULE-BOUND STARCH SYNTHEASE (GBSSI) was used in this study, because Small (2004) found that it can be used to distinguish haplotypes within Hibiscus section Muenchhusia, whereas more commonly employed chloroplast DNA and ITS sequences lacked the requisite molecular variation. But because he was focused on deeper phylogenetic divisions, Small (2004) recommended further study of the segregating haplotypes among H. dasycalyx and its congeners with extended sampling. Following Small (2004), heterozygosity in the nuclear sequence data was leveraged by performing pseudo-phasing, to produce diploid haplotype alleles that could be compared within and among the individuals.

Nine H. dasycalyx specimens, 16 H. laevis specimens, and 14 H. moscheutos specimens were collected from wild populations from June-October 2014 (Figs. 1, S2). DNA was extracted from young leaves of each plant using a DNeasy Plant Mini Kit (Qiagen). PCR and sequencing primers are given in Table 1. PCR reactions were performed in $50 \mathrm{ml}$ volumes with the following reaction components: $35.75 \mu \mathrm{L}$ RNase-free $\mathrm{H}_{2} \mathrm{O}, 5 \mu \mathrm{L}$ 10x ExTaq buffer (TaKaRa), $4 \mu \mathrm{L}$ dNTPs, $2 \mu \mathrm{L} \mathrm{MgCl}_{2}, 2 \mu \mathrm{L}$ BSA, $0.5 \mu \mathrm{L}$ each $2-\mu$ mol primer, $0.25 \mu \mathrm{L}$ ExTaq (TaKaRa), and $1 \mu \mathrm{L} \mathrm{DNA} \mathrm{(Small} \mathrm{2004).} \mathrm{The} \mathrm{addition} \mathrm{of} \mathrm{bovine} \mathrm{serum} \mathrm{albumin} \mathrm{(BSA)} \mathrm{was} \mathrm{used} \mathrm{to} \mathrm{help} \mathrm{improve}$ the amplification of difficult templates. PCR cycling conditions used for the amplification of the GBSSI nDNA were: 30 cycles each of denaturation at $94^{\circ} \mathrm{C}$ for 30 seconds, primer annealing at $60^{\circ} \mathrm{C}$ for 30 seconds, primer extension at $72^{\circ} \mathrm{C}$ for 2 minutes. A final extension step consisted of 5 minutes at $72^{\circ} \mathrm{C}$ (Small 2004). All PCR reactions were performed in Eppendorf Mastercycler personal thermal cyclers.

Verification of PCR product amplification was performed via gel electrophoresis. PCR products were purified prior to sequencing with illustra MicroSpin G-50 Columns (GE Healthcare). Purified PCR products were sent to Eurofins MWG Operon to be sequenced on an ABI 3730xl DNA sequencer. Sequencher 5.2.4 (Gene Codes Corporation, Ann Arbor, Michigan) was used to manually proofread and edit sequenced DNA. ClustalW (Thompson et al. 1994) was used to align all sequences before a final round of editing. Exon regions of all sequences were removed and intron regions were spliced together using Mesquite 3.01 (Maddison \& Maddison 2014). All analyses were carried out using the concatenated intronic regions. The sequence data is available on GenBank (accession numbers MW248970 - MW249007).

Heterozygosity in the data was leveraged to perform pseudo-phasing of haplotypes using the ExcoffierLaval-Balding (ELB) algorithm (Excoffier 2003) in Arlequin v. 3.5.2.2 (Excoffier \& Lischer 2010). The ELB algorithm is well suited to problems involving many loci and/or relatively large genomic regions, including those with variable recombination rates, and it is robust to missing data. Furthermore, it provides better local estimation of gametic phase than the PHASE (Stephens et al. 2001) or HTYPER (Niu et al. 2002) programs, while its global accuracy is broadly similar (Excoffier 2003).

To visualize the haplotypes and their relationships to one another, a maximum likelihood (ML) tree for the intron region of the GBSSI gene was generated using PhyML 3.1 (Guindon et al. 2010). To statistically support the ML gene phylogeny, a non-parametric bootstrap resampling using 1000 bootstrap replicates was performed (Felsenstein 1981). jModeltest 2.16 v20140903 (Darriba et al. 2012) identified HKY85 as the best model of sequence evolution. The ML tree was rooted using a sequence from H. trionum (Small 2004; GenBank accession No. AY341422) as the outgroup species.

Genome-wide admixture analysis.-Three H. dasycalyx specimens, three morphologically hybrid specimens, two H. laevis specimens, and one H. moscheutos specimen, all from East Texas, were used for this portion of the study. The three H. dasycalyx specimens, the three morphological hybrids, as well as one of the H. laevis specimens, were collected in October 2016 from Boggy Slough (http://www.conservationfund.org/projects/ boggy-slough), a large conservation easement located in the Neches River floodplain on the border of Trinity and Angelina Counties. Another H. laevis specimen came from Striker Creek in Cherokee County, and the H. moscheutos specimen was collected in Rusk County (Figs. 1, S3). 
TABLE 1. GBSSI amplification (Amp) and sequencing (Seq) primers used in this study.

\begin{tabular}{llll}
\hline Primer & Sequence $\left(5^{\prime}\right.$ to 3 $\left.^{\prime}\right)$ & Amp/Seq & Reference \\
\hline IF & CTG GTG GAC TCG GTG ATG TTC TTG & Amp & Evans et al. 2000 \\
$9 R$ & CTC TTC TAG CCT GCC AAT GAA CC & Amp & Evans et al. 2001 \\
$3 R$ & TCR AGG AAC AYR GGG TGA TC & Seq & Small 2004 \\
$3 \mathrm{~F}$ & ACT GTY OGR TTC TTC CAC & Seq & Small 2005 \\
$6 R$ & AGA GCA GTG TGC CAA TCA TTG & Seq & Small 2006 \\
$8 R$ & TCA CCR GAW ACA AGC TCC TG & Seq & Small 2007 \\
$8 \mathrm{~F}$ & CCT GTC AAG GGA AGG AAA AT & Seq & Small 2008 \\
\hline
\end{tabular}

DNA was extracted from young leaves of each plant using a DNeasy Plant Mini Kit (Qiagen). The DNA preparations were then sent to SNPSaurus for Nextera-tagmented, reductively-amplified DNA (nextRAD) genotyping (Russello et al. 2015). This next-generation sequencing method identifies thousands of polymorphic loci genome-wide, and is newer and more cost-effective than the RAD-seq approached used for our previous genome-wide analysis. The standard SNPSaurus methods were followed. Genomic DNA was converted into nextRAD genotyping-by-sequencing libraries as in Russello et al. (2015). Genomic DNA was first fragmented with Nextera reagent (Illumina, Inc), which also ligates short adapter sequences to the ends of the fragments. The Nextera reaction was scaled for fragmenting $15 \mathrm{ng}$ of genomic DNA. Fragmented DNA was then amplified for 26 cycles at 73 degrees, with one of the primers matching the adapter and extending nine nucleotides into the genomic DNA with the selective sequence GTGTAGAGC. Thus, only fragments starting with a sequence that can be hybridized by the selective sequence of the primer will be efficiently amplified. The nextRAD libraries were sequenced on a HiSeq 4000 with one lane of 150 bp reads (University of Oregon). The genotyping analysis used custom scripts (SNPsaurus, LLC) that trimmed the reads using bbduk (BBMap tools; Li et al. 2009). Next, a de novo reference was created by collecting 10 million reads in total, evenly from the samples, and excluding reads that had counts fewer than eight or more than 1000. The remaining loci were then aligned to each other to identify allelic loci and collapse allelic haplotypes to a single representative. All reads were mapped to de novo reference with an alignment identity threshold of 90\% using bbmap (BBMap tools). Genotype calling was done using Samtools and bcftools. The resulting VCF file was filtered to remove alleles with a population frequency of less than $15 \%$. Loci were removed that were heterozygous in all samples or had more than two alleles in a sample (suggesting collapsed paralogs). Sequence data has been archived at Data Dryad (Banta 2020).

The potential number of genetic clusters and the membership of each individual were estimated using STRUCTURE Ver. 2.3.4 (Pritchard et al. 2000). The software uses Markov chain Monte Carlo (MCMC) simulations to estimate those parameters, with the number of clusters to be tested (K) specified by the user (BlancoBercial \& Bucklin 2016). Modifications to the default parameters were made following Wang (2017), to account for small sample sizes and unbalanced sampling. Specifically, the alternative ancestry prior was used (a calculated separately for each inferred ancestral population), along with a much smaller initial a of 0.25 , and setting the allele frequencies among the inferred ancestral populations to uncorrelated. The MCMC simulation was run for 100,000 iterations, after a burn-in period of 10,000 iterations. The traces were examined graphically to confirm chain convergence. The most likely $K$ (number of ancestral populations) was inferred following Evanno et al. (2005). For each value of $K$ the genetic ancestry of each individual was estimated based on an admixture model without any prior population assignment. For the entire population set, $\mathrm{K}$ ranged from one to nine. The optimal K was chosen by having the lowest log-likelihood (Sokal \& Rohlf 1995).

RESULTS

\section{Genome-wide phylogenomic analysis}

The number of candidate variants from the RAD-seq analysis passing all filters was 11,660. The rooted maximum likelihood tree (ML, reporting bootstrap values) and the Bayesian coalescent tree (BCT, reporting 
posterior probabilities) show $H$. dasycalyx and $H$. laevis to be more closely related to each other than either are to H. moscheutos, with high support (ML=100, BCT=100; Fig. $2 \& 3$ ). This corresponds to the Group I (H. moscheutos) and Group II (H. dasycalyx and H. laevis) clades that Wise and Menzel (1971) and Small (2004) found. The ML phylogeny further suggests $H$. laevis and $H$. dasycalyx are reciprocally monophyletic, with high support ( $>=90$ ) and show only minor unresolved internal nodes (Fig. 2). The Bayesian analysis, on the other hand, suggests $H$. dasycalyx is nested within H. laevis, also with high support (100) and only minor unresolved internal nodes (Fig. 3).

\section{Ecological niche modeling}

The observed I and $D$ values, quantifying differences in habitat associations between pairs of species, are compared to the permuted $5 \%$ and $10 \%$ critical thresholds from the permutation analysis. If the observed I or $D$ value is less than the $5 \%$ critical I or D threshold, then the pair of species are significantly different in their habitat associations; if the observed I or D value is less than the $10 \%$ critical I or D threshold, but not the 5\% critical I or $D$ threshold, then the pair of species are marginally significantly different in their habitat associations. We found that $H$. dasycalyx and $H$. laevis were significantly different or marginally significantly different in their habitat associations from H. moscheutos, but that $H$. dasycalyx and H. laevis were not significantly different or marginally significantly different in their habitat associations from each other (Table 2). Therefore, we remodeled habitat suitability with $H$. dasycalyx and H. laevis combined since they were ecologically indistinguishable from one another. We then found that $H$. laevis $+H$. dasycalyx combined together were marginally significantly different in their habitat associations from $H$. moscheutos according to the I statistic, and significantly different in their habitat associations from $H$. moscheutos according to the D statistic (Table 2).

We present the ecological niche modeling results below for (a) H. moscheutos modeled by itself and (b) $H$. laevis $+H$. dasycaly $x$ combined together, because these were the only ecological niche models that were distinct from one another according to the permutation tests.

The average test AUC value (based on the set-aside test points used for verification) for H. laevis + dasycalyx was 0.914 , and for $H$. moscheutos it was 0.787 ; both are above 0.75 and therefore are considered sufficiently useful to forecast suitable habitat (Elith 2002). Areas of highest suitability for Hibiscus dasycalyx / H. laevis were found along the Neches River and the Angelina River and their tributaries, the tributaries of the Sabine River, one small group of tributaries of the Trinity River, and the tributaries of Caddo Lake on the border with Louisiana, especially Little Cypress Bayou. Areas of highest suitability for Hibiscus moscheutos were more eclectic, with most suitable habitat found along the middle section of the Neches River and some of its tributaries, the lower Sabine River on the border with Louisiana near the Gulf of Mexico, and tributaries of: Caddo Lake, the lower Trinity River, the upper section of the Neches River, the upper section of the Angelina river, and the upper Sabine river (see the Supplemental Information).

For H. laevis $+H$. dasycalyx modeled together, the depth to the seasonally-high water table was the most important variable contributing to the model fit, followed by erodibility, slope, calcium carbonate concentration, and liquid limit of the soil layer (Table 3). The most suitable habitat had very low calcium carbonate content, as close to zero as possible, and higher levels of calcium carbonate resulted in a drop-off in habitat suitability (Fig. 4a). Soil erodibility yielded two peaks of suitability, one peak in soils with erodibility of 0.28 and the other (higher) peak in soils with erodibility of 0.46 and higher (Fig. 4b); the second peak of suitability in highly erodible soil is consistent with flood plain alluvium. The liquid limit of the soil layer yielded two peaks of suitability, with one peak at around 36\% moisture of the soil by weight, and the other peak at about $69 \%$ moisture by weight (Fig. 4c); the second peak is consistent again with flood plain alluvium. The most suitable habitat had no slope, and habitat suitability dropped off steeply with increasing slope (Fig. 4d), consistent with a plant that lives in a floodplain. Habitat suitability peaked in soils with a depth of around 4-6 cm to the seasonally-high water table, and dropped off at higher and lower values (Fig. 4e); this is consistent with a plant that lives close enough to the water table to get flooded regularly without being perennially submerged. 


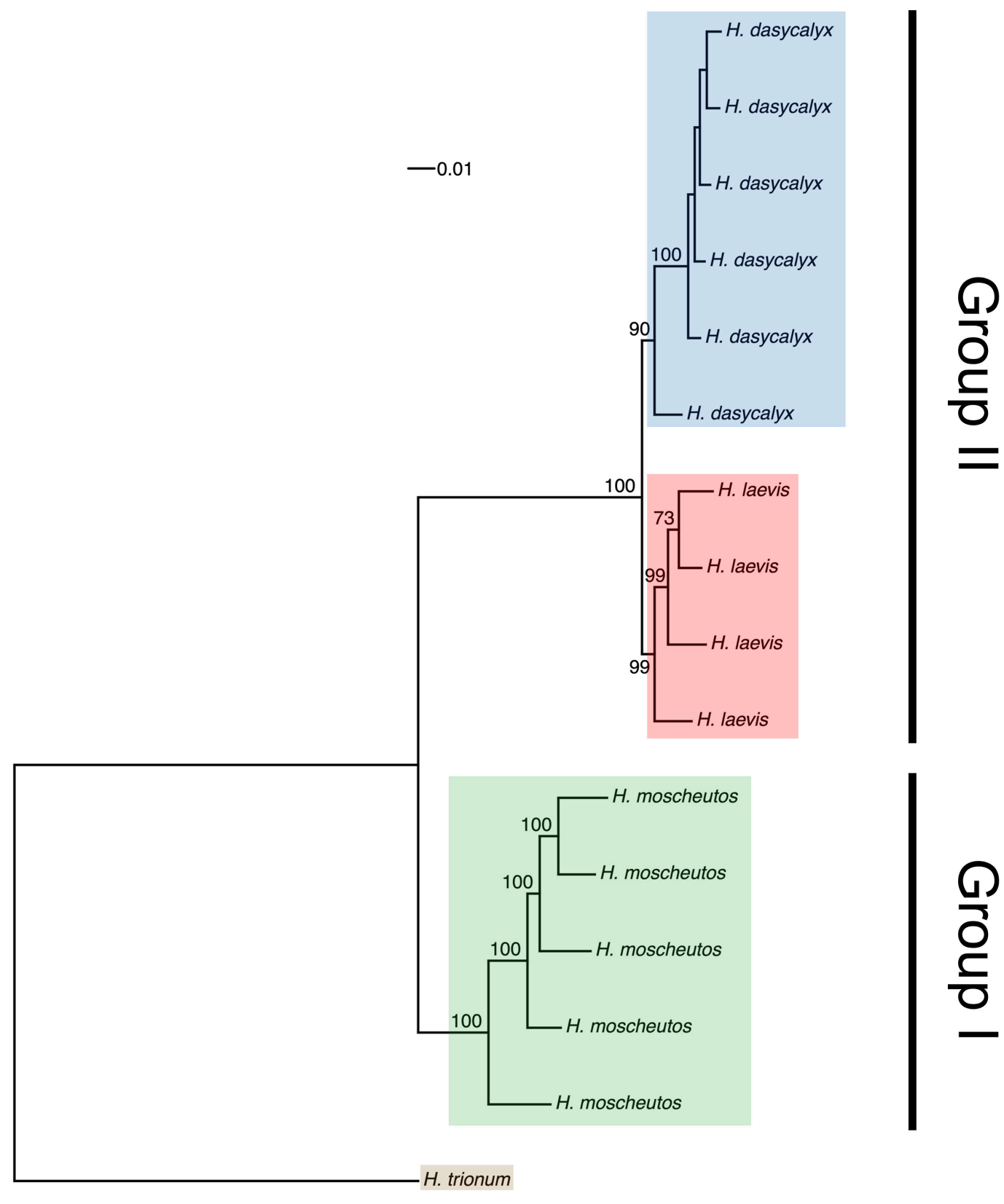

Fig. 2. Rooted maximum likelihood tree showing phylogenetic relationships of Hibiscus dasycalyx, H. laevis, and H. moscheutos inferred from genomewide RADseq markers, with proportional branch lengths. Bootstrap support $>70 \%$ is shown at the nodes. Blue represents $H$. dasycalyx, red represents H. laevis, green represents H. moscheutos, and brown represents the outgroup, H. trionum. 


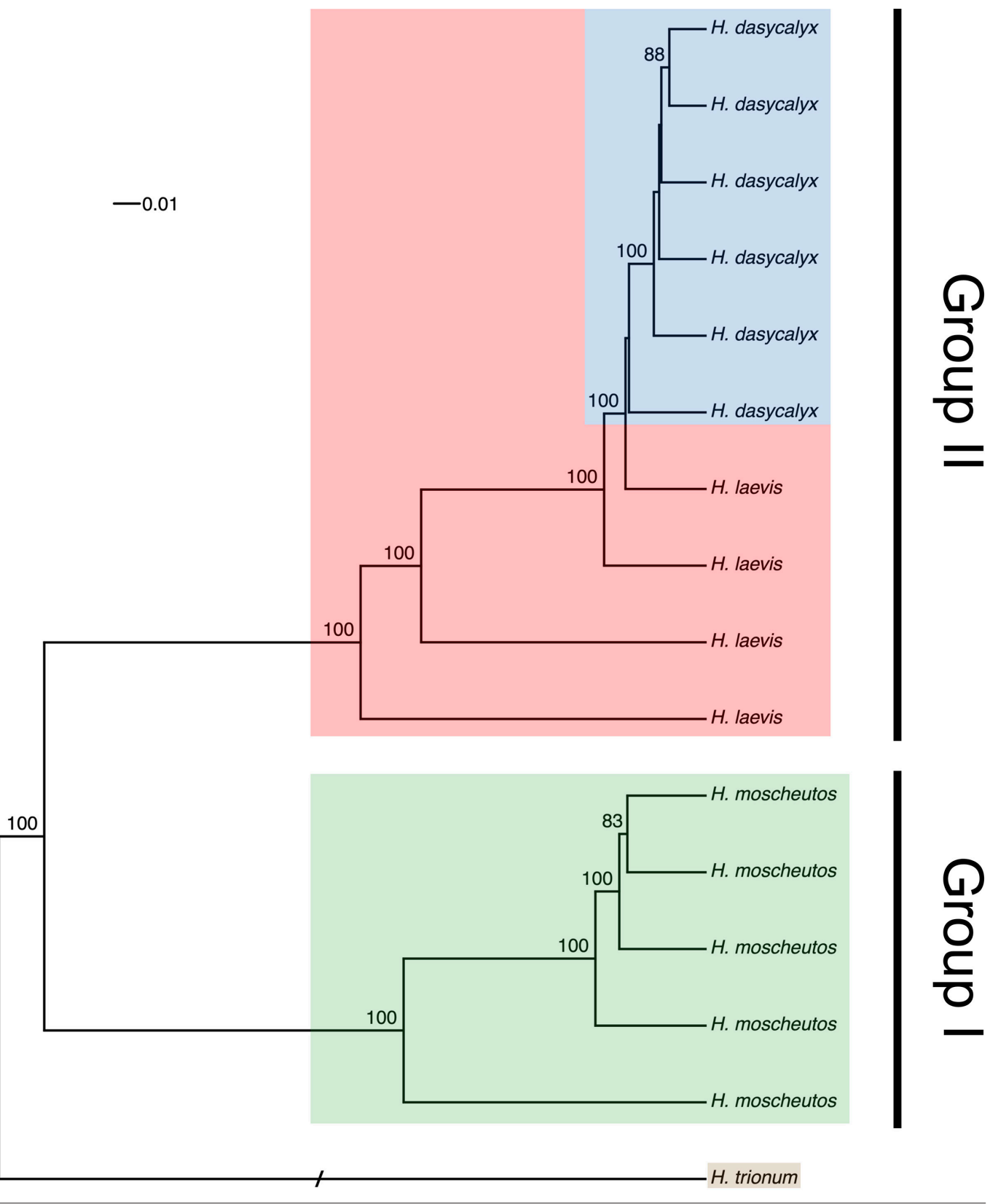

FIG. 3. Bayesian coalescent tree showing phylogenetic relationships of Hibiscus dasycalyx, H. laevis, and $H$. moscheutos inferred from genome-wide RAD-seq markers, with proportional branch lengths. Posteri-or probabilities greater than $70 \%$ are shown at the nodes. Blue represents $H$. dasycalyx, red represents $H$. laevis, green represents $H$. moscheutos, and brown represents the outgroup, $H$. trionum. The slash on the outgroup branch indicates that the length has been shortened for visualization purposes. 
TABLE 2. Observed / values and D-values and critical / values and D-values from the permutation tests carried out for three species of rose mallow. Significant results (non-identical niches) occur when the observed value is below the $5 \%$ or $10 \%$ critical values from the permutation analyses. Comparisons that are significantly or marginally significantly different, either according to / or $D$, are highlighted.

\begin{tabular}{|c|c|c|c|c|c|c|}
\hline Species Comparison & Observed / & $5 \%$ Critical / & $10 \%$ Critical / & Observed $D$ & $5 \%$ Critical $D$ & $10 \%$ Critical $D$ \\
\hline H. dasycalyx vs. H. laevis & 0.7706 & 0.6591 & 0.6899 & 0.5461 & 0.3808 & 0.4247 \\
\hline H. dasycalyx vs. H. moscheutos & 0.6807 & 0.6588 & 0.7646 & 0.3984 & 0.3924 & 0.4915 \\
\hline H. laevis vs. H. moscheutos & 0.8358 & 0.8435 & 0.8762 & 0.5440 & 0.5755 & 0.6202 \\
\hline $\begin{array}{l}\text { H. dasycalyx }+H . \text { laevis vs. } \\
\text { H. moscheutos }\end{array}$ & 0.8367 & 0.8302 & 0.8625 & 0.5442 & 0.5921 & 0.6141 \\
\hline
\end{tabular}

TABLE 3. Summary information for the ecological niche model of Hibiscus laevis $+H$. dasycalyx (modeled together) as well as H. moscheutos, in rows. The test AUCS (unshaded column) and test gains (grey-shaded columns) are presented, including the test gains for models fit with only one single variable from the set: calcium carbonate percentage, erodibility, liquid limit of the soil layer, slope of the map unit, and depth to the seasonally-high water table. The importance of a variable to the full model can be gauged by how much of the gain of the full model is accounted for by the gain of the model built with only that one variable.

\begin{tabular}{|c|c|c|c|c|c|c|c|}
\hline \multirow{3}{*}{ Species } & \multirow{3}{*}{$\begin{array}{l}\text { Test } \\
\text { AUC }\end{array}$} & \multirow{3}{*}{$\begin{array}{l}\text { Full } \\
\text { Model }\end{array}$} & \multirow{3}{*}{$\begin{array}{l}\text { Only } \\
\mathrm{CaCO}_{3}\end{array}$} & \multirow{3}{*}{$\begin{array}{l}\text { Only } \\
\text { Erodibility }\end{array}$} & \multicolumn{2}{|l|}{ Test Gain } & \multirow{3}{*}{$\begin{array}{l}\text { Only Water } \\
\text { Table Depth }\end{array}$} \\
\hline & & & & & Only Liquid & Only & \\
\hline & & & & & Limit & Slope & \\
\hline H. laevis + H. dasycalyx & 0.914 & 1.350 & 0.225 & 0.880 & 0.201 & 0.684 & 0.917 \\
\hline H. moscheutos & 0.787 & 0.670 & 0.247 & 0.377 & 0.546 & 0.238 & 0.206 \\
\hline
\end{tabular}

For H. moscheutos, the liquid limit of the soil layer was the most important variable contributing to model fit (Table 3), followed by erodibility, calcium carbonate concentration, slope, and depth to the seasonally-high water table. Habitat suitabilities for $\mathrm{H}$. moscheutos as a function of calcium carbonate concentration and erodibility were largely similar to the corresponding habitat suitability functions for H. laevis $+H$. dasycalyx modeled together (Fig. 4a, b). Key differences in the habitat suitabilities of H. moscheutos versus H. laevis $+H$. dasycalyx modeled together emerge when examining habitat suitabilities as a function of the other variables. Specifically, H. moscheutos is much less tolerant of soils with a low liquid limit (Fig. 4c) and it is more tolerant of soils with steeper slopes (Fig. 4d) and more extreme depths (both higher and lower depths) to the seasonally-high water table (Fig. 4e). Taken together, this shows that H. moscheutos is comfortable growing in more water-logged, erodible, less well-drained areas than the more strictly floodplain-restricted H. laevis + H. dasycalyx, where flooding is more strictly seasonal.

\section{Molecular evidence of hybridization}

Analysis of segregating nuclear haplotypes.-1,867 nucleotides of the 1,927 nucleotide GBSSI gene were sequenced and aligned. With the exon excised, the intron-only alignment consisted of 1,089 nucleotides of which 17 were variable. Interestingly, H. laevis individuals contained no heterozygosity, whereas H. dasycalyx individuals were heterozygous at an average of 1.1 nucleotide sites (range 0-3 sites) and H. moscheutos individuals were heterozygous at an average of 1.8 nucleotide sites (range 0-6 sites).

After pseudophasing, multiple isogenic haplotypes of GBSSI were recovered (Fig, 5). The H. moscheutos haplotypes were distinguished from those of $H$. dasycalyx and $H$. laevis with moderate bootstrap support (Fig. 5 haplotypes H-P), once again recovering the Group I (H. moscheutos) and Group II (H. dasycalyx and H. laevis) clades that Wise and Menzel (1971) and Small (2004) found. The relationships of the H. dasycalyx and H. laevis haplotypes to one another, however, were not well resolved. Notwithstanding, there were multiple, distinct isogenic haplotypes within the $H$. dasycalyx-H. laevis clade with different isogenic sequences (Fig. 5 haplotypes A-E). Haplotypes B, C, and D contained exclusively H. dasycalyx specimens, and haplotypes F and G contained exclusively H. laevis specimens. Haplotype A was a large isogenic group containing mostly H. laevis specimens, along with alleles from three H. dasycalyx specimens. Haplotype E contained mostly H. dasycalyx specimens, along with alleles from one H. laevis specimen. 

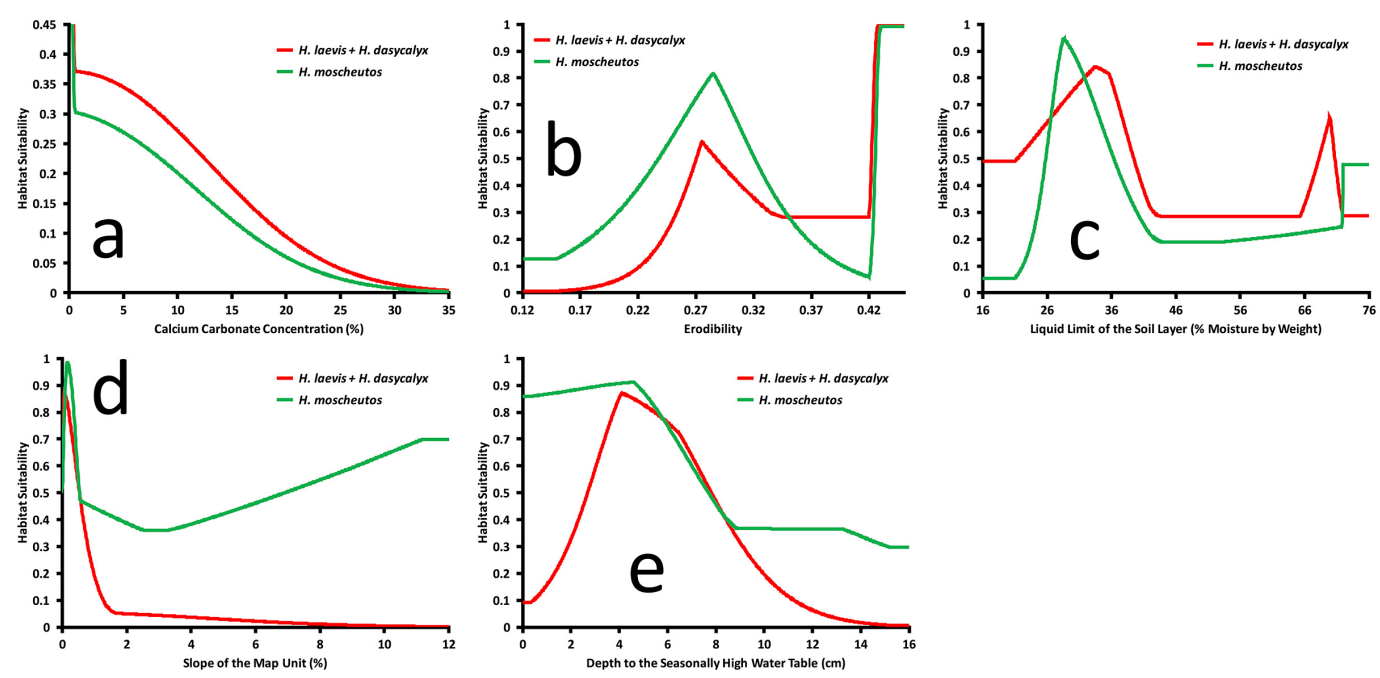

FIG. 4. Average habitat suitability in terms of (a) calcium carbonate concentration, (b) erodibility, (c) liquid limit of the soil layer, (d) slope of the map unit, and (e) depth to the seasonally-high water table. The red line is Hibiscus laevis + H. dasycalyx (modeled together) and the green line is H. moscheutos.

Genome-wide admixture analysis. - The Bayesian clustering analysis was initially performed on three $H$. dasycalyx specimens, two H. laevis specimens, one H. moscheutos specimen, and three morphological hybrids. In that case, the number of candidate variants from the nextRAD analysis passing all filters was 13,337 . The optimal number of inferred ancestral groups (K) was two (Fig. S5), with H. moscheutos completely differentiated from $H$. laevis, H. dasycalyx, and the morphological hybrids, and no other distinctions or any admixture identified (Fig. S6). Because H. moscheutos is more distantly related to H. dasycalyx and H. laevis (see results above), we repeated the analysis excluding H. moscheutos. In that case, the number of candidate variants passing all filters was 5,546. The optimal number of ancestral groups was five (Fig. S7). There were two inferred $H$. dasycalyx ancestral groups and two inferred H. laevis ancestral groups (Fig. 6). One of the morphological hybrids clustered with one of the $H$. dasycalyx groups, and another morphological hybrid was a mixture of two of the H. dasycalyx groups as well as one of the H. laevis groups; the third morphological hybrid had a unique genetic profile that did not cluster with, or have any apparent contributions from, any of the other groups.

\section{DISCUSSION}

\section{General overview}

This project applied multiple approaches to inform the hybridization risk to H. dasycalyx from $H$. laevis or $H$. moscheutos. Using thousands of unbiased, genome-wide markers (Davey et al. 2011), we sought to establish which species was more closely related to $H$. dasycalyx. Previous work with these species has suggested that $H$. laevis is the closest relative (Blanchard 1976; Klips 1995; Small 2004), but these studies used morphology (Blanchard 1976), isozymes (Klips 1995), or a single gene (Small 2004), which cannot yield robust conclusions about the true relationships among taxa (Young \& Gillung 2020), and can even identify the wrong sister taxa and outgroup (Liu \& Pearl 2007; Berger \& Stamatakis 2010; Berger et al. 2011; e.g., Rogers \& Gibbs 2014). We sought to further test the level of ecological relatedness among species, which has not been studied before in this group. Ecological isolation is an important reproductive isolating mechanism, especially in the early stages of speciation when other barriers to gene flow (such as sexual or genetic incompatibility) are not well developed (Coyne \& Orr 2004; Thompson et al. 2005; Gow et al. 2007; Hendry et al. 2007; Schluter 2009). The only Hibiscus sect. Muenchhusia members that H. dasycalyx co-occurs with are H. laevis and H. moscheutos, so 


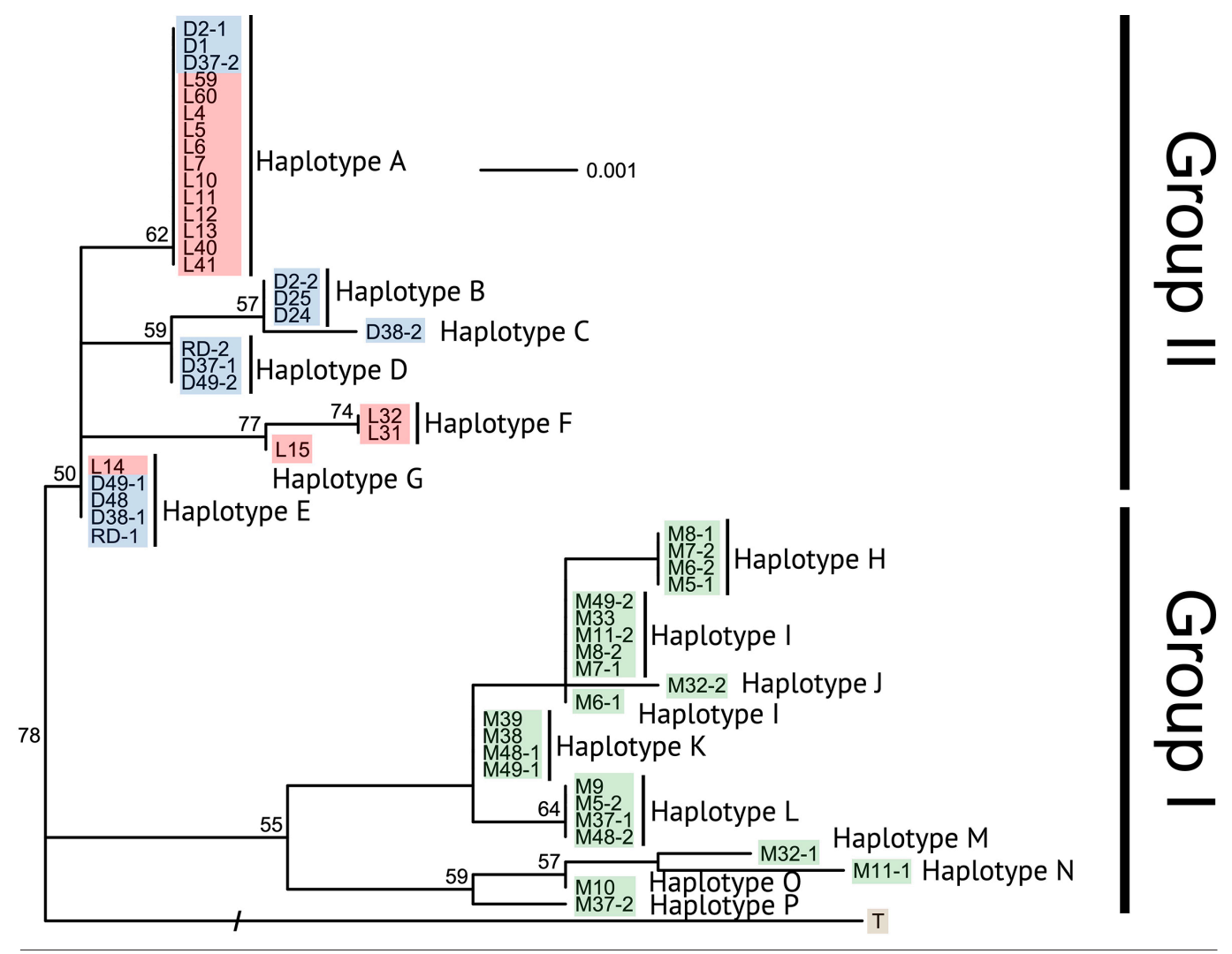

FIG. 5. Rooted maximum likelihood gene tree showing phylogenetic relationships of Hibiscus dasycalyx, H. Iaevis, and H. moscheutos inferred from GBSSI intron sequences, with proportional branch lengths. When heterozygotes were present, each pseudophased allele was analyzed separately, as indicated by the "-1" and "-2" suffixes. Bootstrap values $50 \%$ or greater are shown at each node. Each individual (tip) is color-coded by species. Blue represents $H$. dasycalyx, red represents $H$. laevis, green represents $H$. moscheutos, and brown represents the outgroup, $H$. trionum. The slash on the outgroup branch indicates that the length has been shortened for visualization purposes. Distinct isogenic haplotype groups are indicated with haplotype group labels A-P.

they are the only two potential hybridizers within its range. Our results suggest that $H$. dasycalyx is not only very closely related and ecologically similar to its common congener $H$. laevis, but also that $H$. laevis is actually interbreeding with H. dasycalyx. Unlike previous work by Small (2004), we did not find evidence of hybridization between $H$. dasycalyx and $H$. moscheutos. Based on its more distant relatedness to $H$. dasycalyx, its ecological dissimilarity, and the lack of evidence of hybridization with H. moscheutos turning up in our study, combined with the fact that it is less successful at crossing with $H$. dasycalyx under experimental settings, we believe that $H$. moscheutos is far less likely to hybridize with $H$. dasycalyx in the wild than H. laevis. Therefore, we believe that $H$. laevis poses a greater threat to $H$. dasycalyx.

\section{Genome-wide phylogenomic analysis}

In the modern genomics era (Roff 2007; Hill 2012), high-density, genome-wide sequencing presents an opportunity to better clarify the relationships among species and thereby make more informed conservation decisions (Andrews et al. 2016; Young \& Gillung 2020). A genome-wide phylogenetic study, involving multiple individuals and thousands of unbiased markers, can help to understand which species poses the greatest hybridization threat to H. dasycalyx, because more closely related species should have accrued fewer reproductive isolating mechanisms, all else being equal (Muller 1942; Matute et al. 2010; Fitzpatrick et al. 2015). Our 


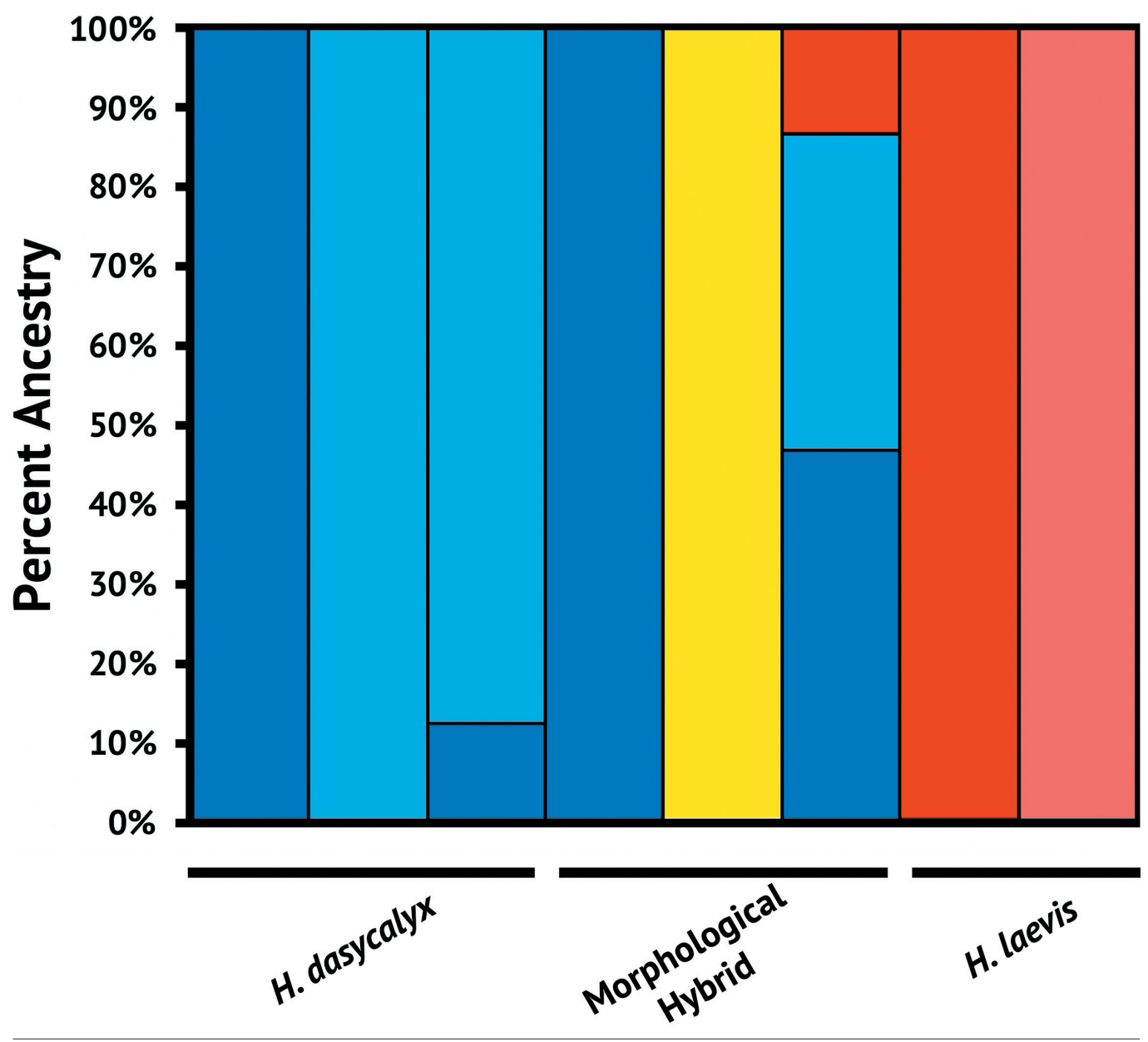

FIG. 6. A graphical representation of the Bayesian cluster analysis, based on genome-wide nextRAD markers, of Hibiscus dasycalyx and $H$. Iaevis specimens, showing the percentages of different inferred ancestries ( $y$-axis) comprising each individual ( $x$-axis). The different inferred ancestral groups are colorcoded blue, light-blue, yellow, red, and light-red. There are two inferred ancestries associated with $H$. dasycalyx (blue and light-blue), and two ancestries associated with H. laevis (red and light-red).

study integrated thousands of genome-wide DNA markers (Davey et al. 2011) to reassess the relationships of the three species, which we've assumed to be well-established as separate species based on their morphological differentiation. Our results confirm previous studies (Blanchard 1976; Klips 1995; Small 2004) that H. dasycalyx is most closely related to H. laevis (Group II), and that these species form a clade that is more distantly related to H. moscheutos (Group I). This is a new piece of evidence, derived with modern methods appropriate in the genomic era, that $H$. dasycalyx is more threatened by hybridization with $H$. laevis than with $H$. moscheutos.

Our findings are particularly noteworthy for the discordance between the maximum likelihood-based and multispecies coalescent-based phylogenetic trees generated from the same genome-wide RADseq dataset. Specifically, the topologies differed within Group II, such that the maximum likelihood method yielded reciprocal monophyly between $H$. dasycalyx and H. laevis with high bootstrap support, whereas the Bayesian coalescent method yielded a nested clade of $H$. dasycalyx within $H$. laevis, with high posterior probability. So which phylogeny should be believed? The maximum likelihood method that we used relies on concatenation (Zhou et al. 2018), which is a "total evidence" approach for phylogenetic inference (Simmons \& Gatesy 2015; Liu et al. 
2019), wherein all loci are considered simultaneously in a single data matrix (Lecointre \& Deleporte 2005). The Bayesian coalescence method that we used, on the other hand, is a "multispecies coalescent" approach (Bryant et al. 2012), which estimates the relative time for mutations among randomly sampled pairs of individuals to coalesce back to common ancestors (Liu et al. 2019). In so doing, it accounts for incomplete lineage sorting among loci as an integral part of the process (Simmons \& Gatesy 2015; Rannala et al. 2020). Incomplete lineage sorting refers to gene lineages that have not yet diverged (i.e., fixation of alternate alleles) after speciation, as when species carry alleles from deeper phylogenetic splits than their speciation event (Charlesworth et al. 2005). The multispecies coalescent approach is generally considered superior to concatenation when the lineages are recent and therefore contain substantial amounts of incomplete lineage sorting (Kubatko \& Degnan 2007; Simmons \& Gatesy 2015; Edwards et al. 2016; Mirarab et al. 2016; Jiang et al. 2020; Rannala et al. 2020). In fact, concatenation can be downright misleading when there is incomplete lineage sorting, directly resulting in highly supported, incorrect topologies (Kubatko \& Degnan 2007; Edwards et al. 2016). The H. dasycalyx-H. laevis clade comprising Group II would seem to fit this criterion, because our results suggest they are very closely related, therefore, they should have more gene tree-species tree discordance among them that is driven by incomplete lineage sorting (Leaché et al. 2014; Angelis \& Dos Reis 2015). However, multispecies coalescence makes unrealistic assumptions as well, such as that only incomplete lineage sorting and no admixture among groups accounts for gene tree-species tree discordance (Simmons \& Gatesy 2015; Liu et al. 2019; Rannala et al. 2020). If any admixture is or has been going on between H. dasycalyx and H. laevis, which seems quite plausible, then this assumption is violated. Furthermore, the concatenation-based approach is actually superior to multispecies coalescence when the gene trees have poor phylogenetic signal (Mirarab et al. 2016). Group II would seem to fit this criterion, since multiple genes have been found to be phylogenetically uninformative for this group (Small 2004), and we additionally found the gene GBSSI to have a weak and noisy phylogenetic signal, at best. There are many other possible sources of the discordance between the two phylogenetic methods (Smith et al. 2015), including our use of default priors in the multispecies coalescent-based approach (Nascimento et al. 2017). Therefore, we believe it is not possible to elevate one phylogenetic inference over the other, and so we cannot tell whether $H$. dasycalyx is reciprocally monophyletic with H. laevis or nested within it paraphyletically. The fact that the conflicting results each have high support emphasizes that the wrong topologies can be highly supported in phylogenetics (Felsenstein 1978; Adkins et al. 2003; Steppan et al. 2004; Pollard et al. 2006; Kubatko \& Degnan 2007; Philippe et al. 2011; Rubin et al. 2012). In fact, our situation is similar to Rodríguez et al. (2017), where they found conflicting topologies for true salamanders, based on concatenation versus multispecies coalescent approaches. Of course, going forward, more sampling and sequencing of individuals may help, because sampling more variation across species, even distant species, may resolve some in-group character conflict causing non-monophyly and polytomies (Nabhan \& Sarkar 2012). But then again, it may not solve the problem, if indeed the methods are fundamentally at odds with each other because of the nature of this closely-related group and the drawbacks of the two methods to query it. This may be a situation where more genome-wide data, even for a larger number of individuals, sequenced at higher-density, cannot determine the true topology of this group, at least by the methods presently available (Philippe et al. 2011).

But even if the Bayesian coalescent phylogeny is correct, with H. dasycalyx nested within H. laevis, we do not believe this warrants a taxonomic reorganization. Clearly both phylogenies show that $H$. dasycalyx is early in its divergence from H. laevis. Reciprocal monophyly is not expected under geographically local models of speciation (i.e., due to founder effects), which are likely to be common forms of speciation in plants (Rieseberg \& Brouillet 1994). Under a scenario where a population or populations of H. laevis or H. laevis-like individuals became isolated in East Texas and diverged to form H. dasycalyx, it would not be surprising that $H$. dasycalyx is paraphyletic with respect to the larger H. laevis species from which it derived. We concur with the large group of systematists, whose letter to the editor of Taxon was coordinated by Nordal and Stedje (2005), that paraphyletic taxa should be accepted. They argue that it is better to leave the current Linnaean classification system intact, which implicitly accommodates paraphyly through its emphasis on important differences, not solely 
descent. Adopting a different classification scheme based on monophyly would, they argue, not only lead to a conglomeration of meaningfully different units and/or a proliferation of meaningless taxa, but it would disrupt conservation efforts during the current era of devastating environmental perturbations and biodiversity loss. $H$. dasycalyx is a morphologically distinct, cohesive unit, and this distinction should not be disregarded solely because some H. laevis sister groups are still extant that render $H$. dasycalyx paraphyletic (if indeed that is the case). If, on the other hand, more sampling and sequencing revealed that $H$. dasycalyx were polyphyletic, spanning multiple different clades, as well as paraphyletic, excluding some individuals within each clade, then we would agree that taxonomic reorganization is warranted (Delić et al. 2017). But that is not what our results suggest. Rather, they suggest either that $H$. dasycalyx is reciprocally monophyletic with its closest relative, $H$. laevis, or that it is emerging from within a single clade of H. laevis. We agree with Padial et al. (2010) and Pante et al. (2015) that, rather than single analyses with binary conclusions, the way forward in taxonomic studies is to use congruence, where species boundaries are delineated based on the culmination of multiple lines of evidence (i.e., morphological, molecular, geographic, and ecological data) that take the continuous nature of the speciation process into account. Therefore, we believe the species status of $H$. dasycalyx, separate from $H$. laevis, should remain intact, since $H$. dasycalyx is morphologically distinct and found within a particular geographic area, and since $H$. dasycalyx is either in the process of diverging from within $H$. laevis or has recently diverged from it.

\section{Ecological niche modeling}

More closely related species are not always more ecologically similar to one another (Losos 2008), but among our species, H. laevis and $H$. dasycalyx are very closely related and ecologically indistinguishable, whereas they are both more distantly related and ecologically dissimilar to $H$. moscheutos. The fact that $H$. dasycalyx and $H$. laevis have indistinguishable habitat preferences suggests there are no ecological barriers to hybridization between $H$. dasycalyx and H. laevis: $H$. laevis can readily invade $H$. dasycalyx habitat and the hybrid offspring of $H$. dasycalyx and $H$. laevis should be at no ecological disadvantage as compared to their parents. By contrast, the fact that $H$. moscheutos has different habitat requirements from $H$. dasycalyx and $H$. laevis suggests that there should be some ecological barriers to hybridization between $H$. moscheutos and $H$. laevis/dasycalyx, either prezygotic (less contact between H. moscheutos and the other two species) or post-zygotic (lower fitness of the H. moscheutos-H. laevis or H. dasycalyx offspring to the habitats of either of the two parents). This is another new piece of evidence, derived with modern ecological methods that have never been applied to this species group before, that $H$. dasycalyx is more threatened by hybridization with H. laevis than with H. moscheutos.

The combined model revealed that $H$. dasycalyx and $H$. laevis are associated with areas that are flat, seasonally flooded, and highly erodible, which are attributes of floodplain alluvium. These associations match the documented habitat preferences of H. dasycalyx (Gould 1975; Warnock 1995; USFWS 2013), which has buoyant seeds that likely rely on water dispersal (Warnock 1995; Scott 1997; USFWS 2013). This highlights the fact that rivers and their tributaries must be free of channelization (natural or artificial) to have the seasonally flooded habitats necessary for these plants, which is not the case for all waterways in East Texas. This also highlights that suitable habitats must be connected by dispersal corridors to other locations where the species is found in order for the seeds to reach those areas.

\section{Molecular evidence of hybridization}

Analysis of segregating nuclear haplotypes.-Our phylogenetic analysis follows up on the one by Small (2004) that focused on Hibiscus section Muenchhusia, including H. dasycalyx, H. laevis, and H. moscheutos. In our case, we focused solely on H. dasycalyx, H. laevis and H. moscheutos, with more samples per species, to search for genetic evidence of hybridization in this species group. We used the same nuclear gene segment used in Small (2004) that was found to have the requisite molecular genetic diversity, and we followed Small (2004) in pseudophasing heterozygous sequences into two haplotypes per individual before visualizing the results in a phylogeny. The idea is to look for evidence of hybridization in the haplogroups: if one or both of an individual's haplotypes are in a haplogroup predominated by members of a different species, then that individual's discordant haplotype(s) could have come into its genome through hybridization and introgression (Small 2004). 
Our expanded dataset largely matched the results in Small (2004) and in previous studies (Blanchard 1976; Klips 1995), with H. dasycalyx and H. laevis GBSSI sequences closely related to each other, and both of those species' sequences more distantly related to H. moscheutos. Yet unlike Small's (2004) study, we did not find evidence of hybridization between $H$. dasycalyx and H. moscheutos: there were no haplotypes from the $H$. moscheutos GBSSI sequences showing up in haplogroups associated with the other two species, and there were no haplotypes from the other two species showing up in haplogroups associated with H. moscheutos specimens. Instead, we only found evidence of hybridization between $H$. dasycalyx and $H$. laevis: haplotypes from some $H$. dasycalyx specimens were found in haplogroups predominantly associated with $H$. laevis specimens, and an H. laevis specimen was in the same haplogroup otherwise made up of H. dasycalyx specimens. This suggests that the hybridization Small (2004) observed between H. dasycalyx and H. moscheutos is rare, and hybridization between $H$. dasycalyx and $H$. laevis is more common. This is yet more new evidence, expanding on a previous study but with more extensive sampling, that $H$. dasycalyx is more threatened by hybridization with H. laevis than with H. moscheutos.

Another difference between our results and those of Small (2004) is that the GBSSI sequences of H. dasycalyx and H. laevis were not well resolved and did not appear to be monophyletic, in contrast to Small's (Small 2004) finding that these gene clades are reciprocally monophyletic. It is important to note that this study is based on a portion of a single nuclear gene. A single gene phylogeny may not accord with the true evolutionary relationships of the taxa in question (Liu \& Pearl 2007; Berger \& Stamatakis 2010; Berger et al. 2011; e.g., Rogers \& Gibbs 2014; Young \& Gillung 2020), so this gene phylogeny does not bear on whether or not H. dasycalyx and $H$. laevis are reciprocally monophyletic species with respect to one another. But it does highlight that gene tree topologies, even when well supported (such as Small 2004), can change when a dataset is expanded.

An alternative explanation for the mixture of $H$. laevis and $H$. dasycalyx haplotypes within the same haplogroups is incomplete lineage sorting. To address this possibility requires an admixture analysis using genome-wide markers, so that differences in the evolutionary histories of individual loci can be averaged out (Yasuda et al. 2015). Such is the approach that we undertook in the following subsection (the genome-wide admixture analysis below). But what our results do emphasize, regardless of whether there is admixture or incomplete lineage sorting, is how genetically similar these two species appear to be. So even if the patterns observed reflect only incomplete lineage sorting, the close genetic relatedness between the two species suggests that hybridization and admixture is more likely than with the more distantly related $H$. moscheutos. This case is strengthened by the fact that $H$. dasycalyx and H. laevis often co-occur together, and that individuals with intermediate morphology are observed in the areas of sympatry (Banta, pers. obs.).

Genome-wide admixture analysis. - As noted in the previous section, individuals with intermediate morphology occur in areas where H. dasycalyx and H. laevis occur in sympatry. One such site is at Boggy Slough in East Texas, which we utilized to test for genomic evidence for admixture by collecting $H$. dasycalyx specimens, H. laevis specimens, and morphologically hybrid (intermediate) specimens, and inferring the ancestral contributions to the genomes of the morphological hybrids (Larcombe et al. 2014; Wielstra et al. 2017) based on thousands of genome-wide markers. The H. moscheutos specimen that we included revealed no evidence of admixture with the other two species, and in fact it was so genetically diverged that it obscured the finer-scale inferred ancestry compositions of $H$. dasycalyx and $H$. laevis; it was only when $H$. moscheutos was removed from the analysis that those contributions were revealed. This adds another piece of new evidence, derived with modern methods, that $H$. moscheutos poses little hybridization threat to $H$. dasycalyx. Only one $H$. moscheutos specimen was included, however, so it is possible that other H. moscheutos sources may show admixture with $H$. dasycalyx. But given how genetically diverged $H$. moscheutos is from $H$. dasycalyx and $H$. laevis, such that it obscures genetic variation among $H$. dasycalyx and $H$. laevis in an admixture analysis, in addition to the other evidence of its divergence presented earlier, we believe the possibility of admixture among H. moscheutos and H. dasycalyx is small.

The inferred ancestry compositions of $H$. dasycalyx and $H$. laevis suggest some genetic structure that is not captured in the other analyses. For instance, there are two inferred ancestors comprising the H. dasycalyx 
specimens, two different inferred ancestors comprising the H. laevis specimens, and one novel ancestry comprising one of the morphological hybrids. But most significantly, one of the morphological hybrids was comprised of inferred ancestries from both $H$. dasycalyx and $H$. laevis, suggesting hybridization. This is another piece of new evidence, derived with modern methods, that $H$. laevis is a hybridization threat to $H$. dasycalyx. The fact that one of the other morphological hybrids from the hybrid zone had $100 \%$ of its ancestry from the $\mathrm{H}$. dasycalyx-inferred ancestors suggests that $H$. dasycalyx can be plastic in its appearance, making it difficult to distinguish from hybrids at least in some circumstances. We speculate that perhaps some of the same conditions that have brought $H$. dasycalyx and $H$. laevis into secondary contact, whatever they may be, may cause some specimens to adopt a more intermediate phenotype, even in the absence of hybridization (Usher et al. 2010). But such a hypothesis would require further investigation. So, too would the ancestry of the one morphological hybrid that did not match our $H$. dasycalyx or H. laevis specimens. But we believe the conclusion is robust that one of our morphological hybrid specimens is admixed between $\mathrm{H}$. dasycalyx and H. laevis. The program we used, STRUCTURE, is very efficient at identifying hybrids and admixture (100\% efficient, according to one study; Sanz et al. 2009). Furthermore, this is based on thousands of genome-wide markers. Finally, while we included only a small number of samples in this analysis, Horras-Portado et al. (2013) note that SNP data like ours requires much smaller numbers of individuals to obtain accurate results than other data such as microsatellites or AFLPs; in fact, Shi et al. (2010) found that as few as four individuals are sufficient when SNPs are utilized. Thus, there is no reason to believe the genomic hybrid we detected, which was also morphologically intermediate, was spurious. How often hybridization is occurring, in this locale and range-wide, requires more study in the future with more samples from more locations. But we believe that the evidence of a hybrid reported here, combined with the genetic and ecological similarity of $H$. dasycalyx and H. laevis reported here, combined with the cross-fertility of $H$. dasycalyx and $H$. laevis in the laboratory reported in previous research (Klips 1995), creates a picture where H. laevis is a greater hybridization threat to H. dasycalyx than H. moscheutos. Furthermore, because of the close genetic relationship and ecological similarity of $H$. dasycalyx and $H$. laevis, we believe there is nothing to stop introgression of $H$. laevis alleles into the $H$. dasycalyx genome when they come into contact, which could eventually result in genetic swamping (Rhymer \& Simberloff 1996; Fitzpatrick et al. 2015; Todesco et al. 2016; Galaverni et al. 2017) that renders H. dasycalyx functionally extirpated or extinct.

\section{CONCLUSIONS}

This research used different individual plants, different locations, and different methods, over time to address the threats posed to H. dasycalyx by its congeners from different perspectives, as well as, from a practical standpoint, to perform more research as funds became available. We believe this approach can serve as a model for conservation research going forward, where funding limitations are chronic (Bakker et al. 2010; Waldron et al. 2013), particularly for rare plants (Balding \& Williams 2016). In our case, any of the individual studies on their own may not be sufficient to come to actionable conclusions about how to conserve H. dasycalyx; however, together, the studies point more robustly towards the conclusion that H. dasycalyx is threatened by H. laevis, and they complement each other in forming this conclusion. Another advantage to our approach from a conservation perspective is that imperiled species are difficult to sample in large quantities, even under the best of circumstances with a large budget, by virtue of the fact that they are rare and, therefore, hard to find or unable to be legally/ethically sampled intensively (Soule 1985; Chadès et al. 2008; Zemanova 2019). As such, spreading out the research effort through time, if planned carefully, can allow for collection of whatever data is feasible at the time, and augmenting the data at a later period. Conservation biology is certainly a "crisis discipline," where information, however imperfect, is needed right away before biodiversity is lost (Soule 1985), and this information should certainly be provided to the relevant stakeholders as soon as possible. But to form more robust and less speculative conclusions, it is often logistically and financially necessary to collect data, and augment it, over time rather than all at once. In that case, we suggest that the data should come from diverse, complementary approaches, such as ours, rather than just the same approach repeated through time, so as to 
make the most out of the limited resources available for the research program and build the most diversified, the most complementary, and ultimately the strongest possible case about what needs to be done for the target species.

We found that $H$. dasycalyx is genomically very closely related to H. laevis, is ecologically indistinguishable from $H$. laevis, and that there is molecular evidence of hybridization occurring between $H$. dasycalyx and H. laevis. By contrast, H. dasycalyx has clearly diverged from H. moscheutos both genomically and ecologically, and we did not find molecular evidence of hybridization between $H$. dasycalyx and H. moscheutos. Taken together, these separate pieces of information make a stronger case that $H$. dasycalyx is threatened by encroachment and hybridization with $\mathrm{H}$. laevis but not $\mathrm{H}$. moscheutos. This was not firmly established before, because the previous phylogenies had been determined using morphology or other techniques with limited marker coverage, which may not reveal the true relationships among species (Liu \& Pearl 2007; Berger \& Stamatakis 2010; Berger et al. 2011; e.g., Rogers \& Gibbs 2014; Young \& Gillung 2020).

But how did H. dasycalyx emerge as a separate species? There must have been a period of isolation to allow the lineage that became $H$. dasycalyx to accumulate genetic and morphological differences, especially in the absence of niche separation (Coyne \& Orr 2004; Kearns et al. 2018). We believe hydrologic barriers are a likely culprit. Previous studies suggest that seeds of H. laevis and H. dasycalyx are dispersed by water (Warnock 1995; Scott 1997; U.S. Fish \& Wildlife Service 2013), which explains why their distributions are restricted to flood plains. Water impoundments for agriculture and municipal purposes are common throughout East Texas and throughout Texas in general (Villarini \& Smith 2013; Wurbs \& Ayala 2014), and these reservoirs cause more frequent and more pronounced flooding (Villarini \& Smith 2013) that could carry H. laevis seeds into East Texas. Another possible cause of hydrology changes that could have allowed H. laevis infiltration is the massive logjam that resulted in Caddo Lake on the Texas-Louisiana border. This logjam occurred naturally during the late 1700s, and drastically changed the hydrological properties of the surrounding landscape to the present day; the lake has since been subject to many other changes that have further altered the water levels (Keeland \& Young 1997). We note that the tributaries of Caddo Lake were identified as highly suitable habitat for $H$. laevis, and therefore they could have represented a dispersal corridor for H. laevis once Caddo Lake allowed its seeds to reach them. Of course, these scenarios would require extensive testing using biogeographic methods (Morrone \& Crisci 1995).

\section{ACKNOWLEDGMENTS}

We would like to thank Jackie Poole, Jason Singhurst, and Anna Strong from the Texas Parks and Wildlife Department, Jeffrey Reid from the U.S. Fish \& Wildlife Service, Minnette Marr from the Lady Bird Wildflower Center, Michael Banks from the Texas Conservation Alliance and Friends of the Neches River, and Kayla Key and En Tze Chong from UT-Tyler for their help with field work. We would also like to thank Ellen Temple from the T. L.L. Temple Foundation for providing housing, and the Texas Land Conservancy, the T.L.L. Temple Foundation, and the Conservation Fund for providing access to their land for field work. Furthermore, we would like to thank Dr. Edwige Moyroud at the University of Cambridge in the U.K. and Duel Glass at the Center for Sustainable Community in Tyler, Texas for providing plant samples. Finally, we would like to thank Dr. André Rinaldo Senna Garraffoni at the University of Campinas Institute of Biology in Brazil, and Josè Manuel Padial at the American Museum of Natural History, for their insightful comments that improved the manuscript. This work was funded by a Section 6 grant from the U.S. Fish and Wildlife Service and Texas Parks and Wildlife Department, as well as grants from Ellen Temple and the T.L.L. Temple Foundation and the National Science Foundation Louis Stokes Alliance for Minority Participation.

SUPPLEMENTARY FIGURES

The supplementary figures are available at: https://doi.org/10.6084/m9.figshare.13237280.v2 


\section{REFERENCES}

Adkins, R.M., A.H. Walton, \& R.L. Honeycutt. 2003. Higher-level systematics of rodents and divergence time estimates based on two congruent nuclear genes. Molec. Phylogen. Evol. 26:409-420.

Aiello-Lammens, M.E., R.A. Boria, A. Radosavlevic, B. Vilela, \& R.P. Anderson. 2015. spThin: An R package for spatial thinning of species occurrence records for use in ecological niche models. Ecography 38:541-545.

Allendorf, F.W., R.F. Leary, P. Spruell, \& J.K. Wenburg. 2001. The problems with hybrids: Setting conservation guidelines. Trends Ecol. Evol. 16:613-622.

AndRews, K.R., J.M. Good, M.R. Millek, G. LuikART, \& P.A. Hohenlohe. 2016. Harnessing the power of RADseq for ecological and evolutionary genomics. Nat. Rev. Genet. 17:81-92.

ANGELIS, K. \& M. Dos REIS. 2015. The impact of ancestral population size and incomplete lineage sorting on Bayesian estimation of species divergence times. Curr. Zool. 61:874-885.

Baird, N.A., P.D. EtTer, T.S. Atwood, M.C. Currey, A.L. Shiver, Z.A. Lewis, E.U. Selker, W.A. Cresko, \& E.A. Johnson. 2008. Rapid SNP discovery and genetic mapping using sequenced RAD markers. PLoS ONE 3:e3376.

BakKer, V.J., J.K. Baum, J.F. Brodie, A.K. Salomon, B.G. Dickson, H.K. GibBS, O.P. Jensen, \& P.B. Mclntrre. 2010. The changing landscape of conservation science funding in the United States. Conserv. Lett. 3:435-444.

Balding, M. \& K.J.H. Williams. 2016. Plant blindness and the implications for plant conservation. Conserv. Biol. 30:1192-1199.

BANTA, J.A. 2020. Hibiscus nextRAD-Seq Conservation Genomics, Dryad, Dataset. https://doi.org/10.5061/Dryad. Dncjsxkxp. Accessed 6 November 2020.

BENTLEY, D.R., ET AL. 2008. Accurate whole human genome sequencing using reversible terminator chemistry. Nature 456:53-59.

BerGeR, S.A. \& A. StAmATAKIs. 2010. Accuracy of morphology-based phylogenetic fossil placement under Maximum Likelihood. In: ACS/IEEE International Conference on Computer Systems and Applications - AICCSA 2010 Pp.1-9.

BerGer, S.A., A. StAMATAKIs, \& R. LüCKING. 2011. Morphology-based phylogenetic binning of the lichen genera Graphis and Allographa (Ascomycota: Graphidaceae) using molecular site weight calibration. Taxon 60:1450-1457.

BLAKE, S.F. 1958. Two species of Hibiscus from Texas. J. Wash. Acad. Sci. 48:277-280.

BlanCHARD, O.J. 1976. A revision of species segregated from Hibiscus sect. Trionum (Medicus) de Candolle sensu lato (Malvaceae).

BLANCO-BERCIAL, L. \& A. BUCKLIN. 2016. New view of population genetics of zooplankton: RAD-seq analysis reveals population structure of the North Atlantic planktonic copepod Centropages typicus. Molec. Ecol. 25:1566-80.

Bryant, D., R. Bouckaert, J. Felsenstein, N.A. Rosenberg, \& A. Roy Choudhury. 2012. Inferring species trees directly from biallelic genetic markers: Bypassing gene trees in a full coalescent analysis. Molec. Biol. Evol. 29:1917-32.

Chadès, I., E. McDonald-Madden, M.A. McCarthy, B. Wintle, M. Linkie, \& H.P. Possingham. 2008. When to stop managing or surveying cryptic threatened species. Proc. Natl. Acad. Sci. U.S.A. 105:13936-13940.

Charlesworth, B., C. Bartolome, \& V. Noel. 2005. The detection of shared and ancestral polymorphisms. Genet. Res. 86:149-157.

Committee on the Status of Endangered Wildlife in Canada. 2014. Swamp rose-mallow (Hibiscus moscheutos) COSEWIC assessment and status report: chapter 3. https://web.archive.org/web/20190509061851 if_/https://www.canada.ca/en/ environment-climate-change/services/species-risk-public-registry/cosewic-assessments-status-reports/swamprose-mallow/chapter-3.html. Accessed 22 June, 2021.

CorrelL, D.S. \& H.B. Correll. 1972. Aquatic and wetland plants of southwestern United States. Environmental Protection Agency, Washington, DC, U.S.A.

CoYne, J.A. \& H.A. OrR. 2004. Speciation. Sinauer, Sunderland, MA, U.S.A.

Daco, L., T. MAURICE, S. MulLer, J. RossA, \& G. Coling. 2019. Genetic status of the endangered plant species Gladiolus palustris in the western part of its distribution area. Conserv. Genet. 20:1339-1354.

DaCosta, J.M., M.J. Miller, J.L. Mortensen, J.M. Reed, R.L. CurRY, \& M.D. Sorenson. 2019. Phylogenomics clarifies biogeographic and evolutionary history, and conservation status of West Indian tremblers and thrashers (Aves: Mimidae). Molec. Phylogen. Evol. 136:196-205.

Darriba, D., G.L. Taboada, R. Doallo, \& D. Posada. 2012. jModelTest 2: More models, new heuristics and parallel computing. Nat Meth 9:772-772.

Davey, J.W., P.A. Hohenlohe, P.D. EtTer, J.Q. Boone, J.M. CAtChen, \& M.L. Blaxter. 2011. Genome-wide genetic marker discovery and genotyping using next-generation sequencing. Nat. Rev. Genet. 12:499-510. 
Delić, T., P. Trontel, M. Rendoš, \& C. Fišer. 2017. The importance of naming cryptic species and the conservation of endemic subterranean amphipods. Sci. Rep. 7:3391.

Drummond, A.J. \& A. RAmbaUt. 2007. BEAST: Bayesian evolutionary analysis by sampling trees. BMC Evol. Biol. 7.

Edwards, S.V., Z. XI, A. Janke, B.C. Falrcloth, J.E. McCormack, T.C. Glenn, B. Zhong, S. Wu, E.M. Lemmon, A.R. Lemmon, A.D. Leaché, L. LIU, \& C.C. DAvis. 2016. Implementing and testing the multispecies coalescent model: A valuable paradigm for phylogenomics. Molec. Phylogen. Evol. 94:447-462.

ELTH, J. 2002. Quantitative methods for modeling species habitat: Comparative performance and an application to Australian plants. In: S. Ferson \& M. Burgman, eds. Quantitative methods for conservation biology Springer, New York, U.S.A. Pp. 39-58.

Evans, R.C., L.A. Alice, C.S. Campbell, E.A. KellogG, \& T.A. Dickinson. 2000. The Granule-Bound Starch Synthase (GBSSI) Gene in the Rosaceae: Multiple loci and phylogenetic utility. Molec Phylogen. Evol. 17(3):388-400.

ExCoffIER, L. 2003. Analysis of population subdivision. In: D. Balding, M. Bishop, \& C. Cannings, eds. Handbook of statistical genetics, 2nd Edition John Wiley and Sons, Ltd., New York, U.S.A. Pp. 713-750.

EXCOFFIER, L. \& H.E.L. LISCHER. 2010. Arlequin suite ver 3.5.2.2: A new series of programs to perform population genetics analyses under Linux and Windows. Molec. Ecol. Resour. 10:564-567.

FAURBY, S., W.L. EISERHARDt, \& J.-C. SVEnNING. 2016. Strong effects of variation in taxonomic opinion on diversification analyses. Methods Ecol. Evol. 7(1):4-13.

Felsenstein, J. 1978. Cases in which parsimony or compatibility methods will be positively misleading. Syst. Zool. 27:401-410.

FELSENSTEIN, J. 1981. Evolutionary trees from DNA sequences: A maximum likelihood approach. J. Molec. Evol. 17:368-76.

FitzPATRICK, B.M., M.E. Ryan, J.R. Johnson, J. CoRUsh, \& E.T. CARTer. 2015. Hybridization and the species problem in conservation. Curr. Zool. 61:206-216.

FrYXeLL, P.A. 1988. Malvaceae of Mexico. Syst. Bot. Monogr. 25:1-522.

Galaverni, M., R. Caniglia, L. Pagani, E. Fabbri, A. Boattini, \& E. Randi. 2017. Disentangling timing of admixture, patterns of introgression, and phenotypic indicators in a hybridizing wolf population. Molec. Biol. Evol. 34:2324-2339.

GARNETT, S.T., \& L. ChRISTIDIS. 2017. Taxonomy anarchy hampers conservation. Nature 546(7656):25-27.

Gow, J.L., C.L. PEICHEL, \& E.B. TAYLOR. 2007. Ecological selection against hybrids in natural populations of sympatric threespine sticklebacks. J. Evol. Biol. 20:2173-2180.

Guindon, S., J.-F. Dufayard, V. Lefort, M. Anisimova, W. HoRdijk, \& O. Gascuel. 2010. New algorithms and methods to estimate maximum-likelihood phylogenies: Assessing the performance of PhyML 3.0. Syst. Biol. 59:307-321.

Heled, J. \& A.J. Drummond. 2010. Bayesian inference of species trees from multilocus data. Molec. Biol. Evol. 27:570-580.

HendRY, A.P., P. NosiL, \& L.H. RiESEBERG. 2007. The speed of ecological speciation. Funct. Ecol. 21:455-464.

Hernandez, P.A., C.H. Graham, L.L. Master, \& D.L. Albert. 2006. The effect of sample size and species characteristics on performance of different species distribution modeling methods. Ecography 29:773-785.

HILL, W.G. 2012. Quantitative genetics in the genomics era. Curr. Genomics 13:196-206.

JIANG, X., S.V. EDWARDS, \& L. LIU. 2020. The multispecies coalescent model outperforms concatenation across diverse phylogenomic data sets. Syst. Biol. 69:795-812.

Katolikova, M., V. Khaitov, R. Vainola, M. Gantsevich, \& P. Strelkov. 2016. Genetic, ecological and morphological distinctness of the blue mussels Mytilus Trossulus Gould and M. Edulis L. in the White Sea. PLoS ONE 11(4):e0152963.

Kearns, A.M., M. Restani, I. Szabo, A. Schroder-Nielsen, J.A. Kim, H.M. Richardson, J.M. Marzluff, R.C. Fleischer, A. Johnsen, \& K.E. OMLAND. 2018. Genomic evidence of speciation reversal in ravens. Nat. Commun. 9:906.

KeELAND, B.D. \& P.J. Young. 1997. Long-term growth trends of baldcypress (Taxodium distichum (L.) Rich) at Caddo Lake, Texas. Wetlands 17:559-566.

KLIPS, R.A. 1995. Genetic affinity of the rare eastern Texas endemic Hibiscus dasycalyx (Malvaceae). Amer. J. Bot. 82:1463-1472.

KUвATKo, L.S. \& J.H. DeGnAn. 2007. Inconsistency of phylogenetic estimates from concatenated data under coalescence. Syst. Biol. 56:17-24.

LaIKRE, L., M.K. SchwartZ, R.S. WAPLES, \& N. RYMAn. 2010. Compromising genetic diversity in the wild: Unmonitored largescale release of plants and animals. Trends Ecol. Evol. 25:520-529.

LameR, J.T., G.G. SASS, J.Q. Boone, Z.H. Arbieva, S.J. Green, \& J.M. Epifanio. 2014. Restriction site-associated DNA sequencing generates high-quality single nucleotide polymorphisms for assessing hybridization between bighead and silver carp in the United States and China. Molec. Ecol. Resour. 14:79-86. 
Langmead, B., C. TrapnelL, M. Pop, \& S.L. Salzberg. 2009. Ultrafast and memory-efficient alignment of short DNA sequences to the human genome. Genome Biol. 10:R25.

Larcombe, M.J., R.E. Vaillancourt, R.C. Jones, \& B.M. Potts. 2014. Assessing a Bayesian approach for detecting exotic hybrids between plantation and native eucalypts. Int. J. For. Res. 2014:650202.

LeachÉ, A.D., R.B. Harris, B. Rannala, \& Z. Yang. 2014. The influence of gene flow on species tree estimation: A simulation study. Syst. Biol. 63:17-30.

LeContre, G. \& P. Deleporte. 2005. Total evidence requires exclusion of phylogenetically misleading data. Zool. Scr. 34:101-117.

Li, H., B. Handsaker, A. Wysoker, T. Fennell, J. Ruan, N. Homer, G. Marth, G. Abecasis, R. Durbin, \& 1000 Genome Project Data Processing Subgroup. 2009. The Sequence Alignment/Map format and SAMtools. Bioinformatics 25:2078-2079.

Liu, L., C. Anderson, D. Pearl, \& S.V. Edwards. 2019. Modern phylogenomics: Building phylogenetic trees using the Multispecies Coalescent Model. In: M. Anisimova, ed. Evolutionary genomics: Statistical and computational methods. Springer, New York, NY, U.S.A. Pp. 211-239.

LiU, L. \& D.K. Pearl. 2007. Species trees from gene trees: Reconstructing bayesian posterior distributions of a species phylogeny using estimated gene tree distributions. Syst. Biol. 56:504-514.

Losos, J.B. 2008. Phylogenetic niche conservatism, phylogenetic signal and the relationship between phylogenetic relatedness and ecological similarity among species. Ecol. Lett. 11:995-1003.

MAdDISON, W.P. \& D.R. MADDISON. 2014. Mesquite: A modular system for evolutionary analysis. Version 3.01 http://mesquiteproject.org.

Matute, D.R., I.A. ButLeR, D.A. TuRISSINI, \& J.A. CoYne. 2010. A test of the snowball theory for the rate of evolution of hybrid incompatibilities. Science 329:1518-1521.

MendozA, E.A. 2004. Genetic diversity within Hibiscus dasycalyx, Hibiscus laevis and Hibiscus moscheutos utilizing ISSR techniques.

MiraraB, S., M.S. BAYZID, \& T. WARnOW. 2016. Evaluating summary methods for multilocus species tree estimation in the presence of incomplete lineage sorting. Syst. Biol. 65:366-380.

MorRone, J.J. \& J.V. CRISCI. 1995. Historical biogeography: Introduction to methods. Ann. Rev. Ecol. Syst. 26:373-401.

MULLER, H.J. 1942. Isolating mechanisms, evolution, and temperature. Biol. Symp. 6:71.

NabHAN, A.R., \& I.N. SaRKAr. 2012. The impact of taxon sampling on phylogenetic inference: A review of two decades of controversy. Brief. Bioinform. 13(1):122-34.

Nascimento, F.F., M.D. ReIS, \& Z. YAng. 2017. A niologist's guide to Bayesian phylogenetic analysis. Nat. Ecol. Evol. $1(10): 1446-54$.

Niu, T., Z.S. QIN, X. XU, \& J.S. LIu. 2002. Bayesian haplotype inference for multiple linked single-nucleotide polymorphisms. Amer. J. Hum. Genet. 70:157-169.

NoRDAL, I. \& B. STEDJE. 2005. Paraphyletic taxa should be accepted. Taxon 54:5.

NosIL, P., B.J. CRESPI, \& C.P. SANDOVAL. 2003. Reproductive isolation driven by the combined effects of ecological adaptation and reinforcement. Proc. R. Soc. Lond. Ser. B-Biol. Sci. 270:1911-1918.

Oregon Department of Transportation. 2005. ODOT erosion control manual: Guidelines for developing and implementing erosion and sediment controls. Appendix B. Prepared by Harza Engineering Company and ODOT Geo/ Environmental Section. https://web.archive.org/web/20170131202303/http://www.deq.state.or.us/wq/stormwater/docs/escmanual/appxb.pdf. Accessed 17 October, 2020.

Padial, J.M., A. Miralles, I. De la Riva, \& M. Vences. 2010. The integrative future of taxonomy. Front. Zool. 7(1):16.

Pante, E., C. Schoelinck, \& N. Puillandre. 2015. From integrative taxonomy to species description: One step beyond. Syst. Biol. 64(1):152-60.

Pearson, R.G., C.J. Raxworthy, M. Nakamura, \& A.T. Peterson. 2007. Predicting species distributions from small numbers of occurrence records: A test case using cryptic geckos in Madagascar. J. Biogeogr. 34:102-117.

Philippe, H., H. Brinkmann, D.V. Lavrov, D.T.J. Littlewood, M. Manuel, G. Wörheide, \& D. Baurain. 2011. Resolving difficult phylogenetic questions: Why more sequences are not enough. PLOS Biol. 9:e1000602.

PHILLIPS, S.J. 2017. A brief tutorial on Maxent. Available from url: http://biodiversityinformatics.amnh.org/open_source/ maxent/. Accessed 18 September, 2019.

PhILLIPS, S.J., R.P. AnDERSON, \& R.E. SchAPIRE. 2006. Maximum entropy modeling of species geographic distributions. Ecol. Model. 190:231-259.

PHILLIPS, S.J. \& M. DuDIK. 2008. Modeling of species distributions with Maxent: New extensions and a comprehensive evaluation. Ecography 31:161-175. 
Pollard, D.A., V.N. Iyer, A.M. Moses, \& M.B. Elsen. 2006. Widespread discordance of gene trees with species tree in Drosophila: Evidence for incomplete lineage sorting. PLOS Genet. 2:e173.

Porras-Hurtado, L., Y. Ruiz, C. Santos, C. Phillips, A. Carracedo, \& M.V. Lareu. 2013. An overview of StRUCTURE: Applications, parameter settings, and supporting software. Front. Genet. 4:98.

Pritchard, J.K., M. Stephens, N.A. Rosenberg, \& P. Donnelly. 2000. Association mapping in structured populations. Amer. J. Hum. Genet. 67:170-181.

R Core TeAm. 2020. R: A language and environment for statistical computing. R Foundation for Statistical Computing, Vienna, Austria. https://www.R-project.org/.

Rannala, B., S. Edwards, A. Leache, \& Z. Yang. 2020. The multi-species coalescent model and species tree inference. Phylogenetics in the Genomic Era. 3-3.

Raxworthy, C.J., C.M. IngRam, N. RabiBisoa, \& R.G. Pearson. 2007. Applications of ecological niche modeling for species delimitation: A review and empirical evaluation using Day Geckos (Phelsuma) from Madagascar. Syst. Biol. 56:907-923.

RHYMER, J.M. \& D. SIMBERLOFF. 1996. Extinction by hybridization and introgression. Ann. Rev. Ecol. Syst. 27:83-109.

RIESEBERG, L.H. \& L. BRoUILLET. 1994. Are many plant species paraphyletic? Taxon 43:21-32.

Rodríguez, A., J.D. Burgon, M. Lyra, I. Irisarri, D. Baurain, L. Blaustein, B. Göçmen, S. Künzel, B.K. Mable, A.W. Nolte, M. Veith, S. Steinfartz, K.R. Elmer, H. Philippe, \& M. Vences. 2017. Inferring the shallow phylogeny of true salamanders (Salamandra) by multiple phylogenomic approaches. Molec. Phylogen. Evol. 115:16-26.

RofF, D.A. 2007. A centennial celebration for quantitative genetics. Evolution 61:1017-1032.

RogerS, J. \& R.A. GIBBS. 2014. Comparative primate genomics: Emerging patterns of genome content and dynamics. Nat. Rev. Genet. 15:347-359.

RoJAS, M. 1992. The species problem and conservation: What are we protecting? Conserv. Biol. 6(2):170-78.

Rubin, B.E.R., R.H. ReE, \& C.S. MoreAu. 2012. Inferring phylogenies from RAD sequence data. PLoS ONE 7:e33394.

Russello, M.A., M.D. Waterhouse, P.D. EtTer, \& E.A. Johnson. 2015. From promise to practice: Pairing non-invasive sampling with genomics in conservation. PeerJ 3:e1106-e1106.

Sanz, N., R.M. Araguas, R. Fernández, M. Vera, \& J.-L. García-Marín. 2009. Efficiency of markers and methods for detecting hybrids and introgression in stocked populations. Conserv. Genet. 10:225-236.

SCHLUTER, D. 2009. Evidence for ecological speciation and its alternative. Science 323:737-741.

SCOTT, S.E. 1997. The horticultural treatment and introduction of a rare wetland plant: Neches River rose mallow (Hibiscus dasycalyx). Master's thesis, Stephen F. Austin State University, Nacogdoches, Texas, U.S.A.

Shi, W., Q. Ayub, M. Vermeulen, R. Shao, S. Zuniga, K. van der GaAg, P. de KnijfF, M. Kayser, Y. Xue, \& C. Tyler-Smith. 2010. A worldwide survey of human male demographic history based on Y-SNP and Y-STR data from the HGDP-CEPH populations. Molec. Biol. Evol. 27:385-393.

SIMMOnS, M.P. \& J. GATESY. 2015. Coalescence vs. concatenation: Sophisticated analyses vs. first principles applied to rooting the angiosperms. Molec. Phylogen. Evol. 91:98-122.

SMALL, R.L. 2004. Phylogeny of Hibiscus sect. Muenchhusia (Malvaceae) based on chloroplast $r p L 16$ and $n d h F$, and nuclear ITS and GBSSI sequences. Syst. Bot. 29:385-392.

SMith, S.A., M.J. Moore, J.W. Brown, \& Y. YANG. 2015. Analysis of phylogenomic datasets reveals conflict, concordance, and gene duplications with examples from animals and plants. BMC Evol. Biol. 15(1):150.

SокAL, R.R. \& F.J. RoHLF. 1995. Biometry: The principles and practice of statistics in biological research. 2nd ed.

SouLÉ, M.E. 1985. What is conservation biology? Bioscience 35:727-734.

StAMATAKIS, A. 2006. RAxML-VI-HPC: Maximum likelihood-based phylogenetic analyses with thousands of taxa and mixed models. Bioinformatics 22.

StePhens, M., N.J. SMith, \& P. Donnelly. 2001. A new statistical method for haplotype reconstruction from population data. Amer. J. Hum. Genet. 68:978-89.

Steppan, S.J., R.M. Adkins, \& J. Anderson. 2004. Phylogeny and divergence-date estimates of rapid radiations in muroid rodents based on multiple nuclear genes. Syst. Biol. 53:533-553.

TeXas Land Conservancy. 2015. Hibiscus Preserve: Houston County. https://web.archive.org/web/20170319235528/ http://www.Texaslandconservancy.Org/Lands/Properties-List/East-Texas/97-Hibiscus-Preserve-Houston-County. Accessed 17 October, 2020.

Texas Parks \& Wildife Department. n.d. Neches River Rose Mallow. https://web.archive.org/web/20200924192230/https:// Tpwd.Texas.Gov/Huntwild/Wild/Wildlife_diversity/Nongame/Listed-Species/Plants/Neches_river_rose_mallow. Phtml. Accessed 17 October, 2020. 
THompson, J.D., D.G. HIGGINs, \& T.J. GIBSON. 1994. CLUSTALW: Improving the sensitivity of progressive multiple sequence alignment through sequence weighting, position-specific gap penalties and weight matrix choice. Nucleic Acids Res. 22:4673-4680.

Thompson, J.D., S. Lavergne, L. Affre, M. Gaudeul, \& M. Debussche. 2005. ecological differentiation of mediterranean endemic plants. Taxon 54:967-976.

Todesco, M., M.A. Pascual, G.L. Owens, K.L. Ostevik, B.T. Moyers, S. Hubner, S.M. Heredia, M.A. Hahn, C. Caseys, D.G. Bock, \& L.H. RieSEBERg. 2016. Hybridization and extinction. Evol. Appl. 9:892-908.

United States Department of Agriculture, National Resources Conservation Service, \& National Soil Survey Center. 1995. State Soil Geographic (STATSG0) Data Base: Data use information. Misc. Publ. No. 1492. http://www.fsl.orst.edu/ pnwerc/wrb/metadata/soils/statsgo.pdf. Accessed 13 September, 2018.

US Fish \& WILDLIFE SERVICE. 2013. 50 CFR Part 17: Endangered and threatened wildlife and plants; designation of critical habitat for Texas Golden Gladecress and Neches River Rose-Mallow; final rule. http://www.gpo.gov/fdsys/pkg/ FR-2013-09-11/pdf/2013-22083.pdf. Accessed 8 September, 2014.

UsheR, A.V., R.J. Whelan, \& D.J. AYRe. 2010. Window of opportunity: An episode of recruitment in a Banksia hybrid zone demonstrates continuing hybridization and phenotypic plasticity. Ann. Bot. 105:419-429.

VILLARINI, G. \& J.A. SMITH. 2013. Flooding in Texas: Examination of temporal changes and impacts of tropical cyclones. J. Amer. Water Resour. Assoc. 49:825-837.

Vuillaume, B., V. Valette, O. Lepais, F. Grandjean, \& M. Breull. 2015. Genetic evidence of hybridization between the endangered native species iguana delicatissima and the invasive Iguana iguana (Reptilia, Iguanidae) in the Lesser Antilles: Management Implications. PloS One 10:e0127575-e0127575.

Waldron, A., A.O. Mooers, D.C. Miller, N. NibBelink, D. Redding, T.S. Kuhn, J.T. Roberts, \& J.L. Gittleman. 2013. Targeting global conservation funding to limit immediate biodiversity declines. Proc. Natl. Acad. Sci. 110:12144.

Walters, A.D., D. Ford, E.T. Chong, M. Williams, N.B. Ford, L.R. Wllliams, \& J.A. Banta. 2017. High-resolution ecological niche modeling of threatened freshwater mussels in east Texas, USA. Aquat. Conserv. Mar. Freshw. Ecosyst. Press.

WANG, J. 2017. The computer program STRUCTURE for assigning individuals to populations: Easy to use but easier to misuse. Molec. Ecol. Resour. 17:981-990.

WARNOCK, M.J. 1995. Status report on Hibiscus dasycalyx. US Fish \& Wildlife Service, Albuquerque, NM, U.S.A.

WARREN, D.L., R.E. GLOR, \& M. TURELLI. 2010. ENMTools: A toolbox for comparative studies of environmental niche models. Ecography 33:607-611.

WarRen, D.L., R.E. GloR, \& M. TuReLli. 2008. Environmental niche equivalency versus conservatism: Quantitative approaches to niche evolution. Evolution 62:2868-2883.

Wielstra, B., T. Burke, R.K. Butuin, A. Avci, N. Üzüm, E. Bozkurt, K. Olgun, \& J.W. Arntzen. 2017. A genomic footprint of hybrid zone movement in crested newts. Evol. Lett. 1:93-101.

Wiens, J.J. \& C.H. Graham. 2005. Niche conservatism: Integrating evolution, ecology, and conservation biology. Ann. Rev. Ecol. Evol. Syst. 36:519-539.

WINTERS, H.F. 1970. Our hardy Hibiscus species as ornamentals. Econ. Bot. 24:155-164.

WISE, D.A. \& M.Y. Menzel. 1971. Genetic affinities of the North American species of Hibiscus sect. Trionum. Brittonia 23:425-437.

WoLock, D.M. 1997. STATSGO soil characteristics for the conterminous United States. Open-file report 97-656. https:// water.usgs.gov/GIS/metadata/usgswrd/XML/muid.xml. Accessed 30 May, 2017.

WurBs, R.A. \& R.A. Ayala. 2014. Reservoir evaporation in Texas, USA. J. Hydrol. 510:1-9.

Yasuda, N., C. TAQuet, S. Nagal, M. Fortes, T.-Y. Fan, S. HARII, T. YoshidA, Y. Sito, \& K. Nadaoka. 2015. Genetic diversity, paraphyly and incomplete lineage sorting of mtDNA, ITS2 and microsatellite flanking region in closely related Heliopora species (Octocorallia). Molec. Phylogen. Evol. 93:161-171.

Young, A.D. \& J.P. GILLung. 2020. Phylogenomics—principles, opportunities and pitfalls of big-data phylogenetics. Syst. Entomol. 45:225-247.

Zemanova, M.A. 2019. Poor implementation of non-invasive sampling in wildlife genetics studies. Rethink. Ecol. 4:119-132.

ZHou, X., X.-X. SHEN, C.T. Hittinger, \& A. Rokas. 2018. Evaluating fast maximum likelihood-based phylogenetic programs using empirical phylogenomic data sets. Molec. Biol. Evol. 35:486-503. 